\title{
The Table of Sixty-One Headings as a Tool for Finding the Intervals between the Recurrence of Paired Year Codes in the Jewish Calendar
}

\author{
Eran Raviv \\ General History: A Science and Halacha Program, Bar Ilan University, Ramat-Gan, Israel \\ Email: Eran.Raviv@biu.ac.il
}

How to cite this paper: Raviv, E. (2020) The Table of Sixty-One Headings as a Tool for Finding the Intervals between the Recurrence of Paired Year Codes in the Jewish Calendar. Open Journal of Applied Sciences, 10, 169-190.

https://doi.org/10.4236/ojapps.2020.104014

Received: January 22, 2020

Accepted: April 27, 2020

Published: April 30, 2020

Copyright $\odot 2020$ by author(s) and Scientific Research Publishing Inc. This work is licensed under the Creative Commons Attribution International License (CC BY 4.0).

http://creativecommons.org/licenses/by/4.0/

\begin{abstract}
This paper presents an additional mathematical tool that can be used to analyze the Jewish calendar. The table of sixty-one headings was prepared in France, seven hundred and fifty years ago as a tool for finding the year codes for the 19-year of a particular cycle of Jewish years. This unique table demonstrated that there are only 61 possible arrangements of the year codes in these 19-year cycles. The table can be used to calculate the intervals between the appearances of a pair or any series of particular year codes. These intervals create a closed path.
\end{abstract}

\section{Keywords}

Calendar, Hebrew Calendar, Sixty-One Headings

\section{Introduction}

The table of sixty-one headings was prepared in France, seven hundred and fifty years ago as a tool for finding the year codes for the 19-year of a particular cycle of Jewish years. The paper is divided into two parts. The first part will explain the use of the table of sixty-one headings and will present an improved version of the table that will demonstrate the repetitiveness of the average occurrence of the new moon ("new moon"). The second part will demonstrate a new method with which one can understand the intervals at which a pair of year codes appear and the mathematical logic of these intervals. This method will be demonstrated on one case.

\section{The Fixed Jewish Calendar Background}

The Fixed Jewish calendar is thought to have been conclusively standardized at 
the beginning of the Tenth century after the publicized dispute between Sa'adia Gaon from Babylon and Aharon Ben Meir from Israel. [1] maintains that this dispute continued for 200 additional years but there is no evidence to support this Theory). The fixed Jewish calendar is based on standard mathematical calculations and not on the sighting of the new moon at the beginning of each month. For a brief explanation of the fixed Jewish calendar, see Appendix 1. This part presents an abbreviated description of the fixed Jewish calendar. For a detailed description see [2].

\section{The Table of 61 Headings}

\subsection{The Author of the Table}

At the beginning of the $13^{\text {th }}$ century, a radically new calendar was publishedthe table of 61 headings. The table of 61 headings has been attributed to the RITZBAH (= Ribah = Rabbi Yitzchak Ben Avraham of Dampier (the grandson of Rabbi Shimon the old of Falaise the brother-in-law of Rabeinu Tam) of France, the brother of the Rash from Shanz' the student of RAbeinu Tam and Ri the old approximately in the year 1200). The table was first (in prunt) publicized in "Yesod Olam" by Rav Yitzchak Hayisraeli and there it is attributed to the later rabbis, without the mention of a specific author. The purpose of this radically new table was to simplify the determination of the year code. By using this table which includes all possibilities of the fixed calendar we can determine the year code of all the years in a 19 -year cycle just by knowing the time of the new moon of the new years of the first year of the cycle.

Haim Yehiel Bornstein [3] attributes the table to RITZBAH one of the writers of the Tosphot on the basis of a statement in the Kolofon of a manuscript of Sefer Evronot from 1566. There is written: "Rabbi Shimon devised 13 rows in order to determine the year codes and Rabbi Yitzchak Ben Avraham his brother devised 61 rows that repeat themselves and the Gaon Nachshon devised 13 rows as written before you and these are not correct".

The original idea on which this table is based is that if we divide all the years since the epoch into cycles of 19 years, we will find only 61 different combinations of year codes! As a result, it is enough to know the time of the new moon of new years of the first year of a cycle in order to determine the year codes for all 19 years.

\subsection{Using the Table of Sixty-One Headings}

In order to use the table, one must first calculate the time of the new moon of New Years of the cycle we want to determine. In the second step, we will find the heading that includes the time of the new moon that we have calculated.

The formula for calculating the new moon of New Years in parts is as follows: 


$$
M=\left[57,444+69,715 * \operatorname{int}\left[\frac{S-1}{19}\right]\right](\bmod 181,440)
$$

Calculating the new moon of New Years is as follows:

From the year, we want to calculate we deduct 1 . We divide the result by 19 . We take the integer of the result and multiply by 69,715 (the remainder of a cycle). We add this to the new moon of year $1(57,444)$ and subtract all the whole weeks.

$S=$ the year (counting from year one in which the new moon was Mon 5 hours and 204 parts).

$M=$ the new moon of New Years of the first year of the 19 year cycle in parts.

Int $=$ the integer of the result of the division.

$M o d=$ the remainder of calculating modulo weeks.

$57,444=$ the new moon of year 1 in parts.

$69,715=$ the remainder of a 19-year cycle in parts.

$181,440=$ the length of a week in parts.

Appendix 2 presents a modified classic table of 61 headings as it appears in the literature.

The column "total parts" indicates the total number of parts between the first and last limits of the parts in that row. The total number of parts in each of the rows is not equal. The total of all the parts in all 61 rows is equal to 181,440 parts, that is the number of parts in a week $(7 \times 24 \times 1,080)$.

Table 1 shows rows number 61 and 1 of the table and only the first 6 years of each cycle.

Row 61 begins with 22,160 parts and ends with (not including) 26,328. Since the table is cyclic, we placed row number 1 under row 61 .

As long as the new moon of New Years of the first year of a cycle falls between Sunday 20 hours and 560 parts $(0,20,560)$ and (but not including) 1, 0, 408 then the year codes of the years in that cycle will be those of row 61 .

$$
5779 \bmod 19=312
$$

Therefore, the year 5779 is the third year of the cycle and it's year code is bfg.

\subsection{The New Moon of the First Year of the Cycle and a Correction to the Limits That Are Needed in the Table}

As has been pointed out in previous publications, (Especially (Raviv [4]) the units digit of the new moon of New Years of the cycle can only be a 4 or a 9 . The first to clearly write this was Avraham Ibn Ezra in Sefer HaIbur (Thank you to

\begin{tabular}{|c|c|c|c|c|c|c|c|c|c|c|}
\hline \multirow{2}{*}{ row } & \multicolumn{4}{|c|}{ Limits of the parameters } & \multirow[b]{2}{*}{1} & \multirow[b]{2}{*}{2} & \multirow[b]{2}{*}{3} & \multirow[b]{2}{*}{4} & \multirow[b]{2}{*}{5} & \multirow[b]{2}{*}{6} \\
\hline & Day & Hour & Parts & Total parts & & & & & & \\
\hline 61 & 0 & 20 & 560 & 22,160 & bdc & erg & bfg & bfe & gda & $\mathrm{crg}$ \\
\hline 1 & 1 & 0 & 408 & 26,328 & bdc & efa & $\operatorname{crg}$ & bfe & gda & $\mathrm{crg}$ \\
\hline
\end{tabular}

Table 1. Rows 1 and 61 
my colleague Shi Walter for bringing this to my attention) as follows: "(The new moon of Tishrei of the first year of the cycle A.R) will always have a 4 in the units digit if it is an odd cycle and a 9 if it is an even cycle" [5]. As a result, the units digit of all the new moons of the New Years have only two possibilities. We therefore should correct the limits in the table to give us 36,288 (181,440 parts in a week/5) possible new moons of New Years of the first year of the cycle. Therefore, the recurrence period of the Jewish calendar is $36,288 \times 19$ years which is 689,472 years [6].

\subsection{Comments on the Corrected Table of 61 Headings (Table 3 ) Below}

The intervals of the headings are corrected so they always have a units digit of 4 or 9.

1) In the table, certain year codes are marked. These are the years in which the year code changes from one row to the next, that is they are the cause of a new row being added to the table.

Example:

In row 1 in Table 3, we see the second and third years marked. This is because the year codes of these years have changed from those in row 61 .

We see that in row 1 (in Table 2) the year code of the second year of the cycle has changed from erg to efa that is the day of the new year has not changed (remains Thursday) but the year has lengthened by one day. The lengthening of the year is due to deferring the new year of the third year from Monday to Tuesday. As the second year cannot be a leap year the deferring must be due to the fact that the new moon occurred on Monday at or after 18 hours. We see therefore that the reason for row 1 being separate from row 61 is the result of a new moon on or after 18 hours on Monday (this can be seen as well in Table 3 below).

2) Similarly, instead of using limits of the rows that add up to 181,440 parts in a week in the new table, we use occurrences of the row which signifies how many times this row can appear in the recurring cycle of years in the calendar $(689,472$ years). Therefore, we have added an additional column called "occurrences" all of which add up to 36,288 representing the total recurrence of the Jewish calendar $(36,288 \times 19=689,472$ years $)$.

Bornstein, who had an inquiring nature, saw that this table could be used for many purposes other than its original intention. He wrote as follows: (Haim Yehiel Bornstein [3] Part 2 p 291) "Anyone can see immediately the practical benefit of this table as it can with only the knowledge of the new moon of the first Tishrei in a cycle, provide us the year codes of all 19 years of that cycle. But its

Table 2. The different between rows 1 and 61 .

\begin{tabular}{ccc}
\hline Row number in the table & $2^{\text {nd }}$ year of the cycle & $3^{\text {rd }}$ year of the cycle \\
\hline 61 & erg & bfg \\
1 & efa & $\mathrm{crg}$
\end{tabular}


Table 3. Corrected table of 61 headings.

\begin{tabular}{|c|c|c|c|c|c|c|c|c|c|c|c|c|c|c|c|c|c|c|c|c|c|c|c|c|}
\hline \multicolumn{25}{|c|}{ Table of 61 headings - Actual limits } \\
\hline \multirow[b]{2}{*}{$\mathrm{n}$} & \multicolumn{4}{|c|}{ Borders } & \multirow[b]{2}{*}{ occurences } & \multicolumn{19}{|c|}{ Year in the cycle } \\
\hline & $|a y| r$ & hc & part & parts & & 1 & 2 & 3 & 4 & 5 & 6 & 7 & 8 & 9 & 10 & 11 & 12 & 13 & 14 & 15 & 16 & 17 & 18 & 19 \\
\hline 1 & 1 & 0 & 409 & 329 & 065 & $\mathrm{ic}$ & fa & crg & $\mathrm{fe}$ & gda & crg & bfe & gdc & efa & cre & gfe & $\mathrm{fc}$ & erg & bde & $\mathrm{gfc}$ & erg & bde & $\mathrm{fc}$ & efc \\
\hline 2 & 1 & 5 & 34 & 7 & 10 & & $a$ & CT & $\mathrm{e}$ & $\mathrm{a}$ & $\mathrm{crg}$ & $\mathrm{fe}$ & gfe & gda & et & gfe & $\mathrm{fc}$ & erg & $\mathrm{de}$ & gfc & $\mathrm{rg}$ & $\mathrm{de}$ & $\mathrm{fc}$ & $\mathrm{fc}$ \\
\hline 3 & 1 & 1 & 44 & 354 & 98 & c) & fa & crg & $\mathrm{e}$ & $\mathrm{aa}$ & $\mathrm{crg}$ & $\mathrm{fe}$ & gfe & gda & $\mathrm{e}$ & gfe & gfc & erg & $\mathrm{de}$ & gfc & $\mathrm{rg}$ & $\mathrm{fg}$ & $\mathrm{dc}$ & efc \\
\hline 4 & 1 & 9 & 24 & & & $\mathrm{e}$ & $\mathrm{da}$ & crg & $\mathrm{fe}$ & gda & crg & bfe & gfe & $\mathrm{da}$ & re & gfe & gfc & erg & $\mathrm{de}$ & gfc & erg & $\mathrm{fg}$ & $\mathrm{dc}$ & efc. \\
\hline 5 & 1 & 9 & 29 & & 535 & fe & da & crg & $\mathrm{fe}$ & gfc & eda & cre & gfe & gda & $\mathrm{re}$ & gfe & gfc & erg & $\mathrm{de}$ & $\mathrm{gfc}$ & erg & $\mathrm{fg}$ & $\mathrm{dc}$ & efc \\
\hline 6 & 1 & 11 & 44 & 44 & 38 & $\mathrm{fe}$ & gda & crg & $\mathrm{fe}$ & gfc & eda & cre & gfe & gfc & erg & bde & gfc & erg & bde & gfc & erg & $\mathrm{fg}$ & $\mathrm{dc}$ & efc \\
\hline 7 & 1 & 22 & 54 & & 4 & e & gda & crg & bfe & gfc & eda & re & gfe & gfc & erg & bde & gfc & erg & bfg & $\mathrm{bdc}$ & erg & $\mathrm{fg}$ & $\mathrm{dc}$ & efc \\
\hline 8 & 1 & 22 & 74 & & 99 & $\mathrm{e}$ & gda & crg & bfe & gfc & eda & cre & gfe & gfc & $\mathrm{rg}$ & bde & gfc & $\mathrm{rg}$ & bfg & $\mathrm{bdc}$ & $\mathrm{erg}$ & $\mathrm{fg}$ & $\mathrm{fe}$ & $\operatorname{gdc}$ \\
\hline 9 & 2 & 0 & 99 & & 35 & $\mathrm{e}$ & $\mathrm{gfc}$ & eda & $\mathrm{re}$ & gfc & eda & re & \begin{tabular}{|l|l|} 
gfe \\
\end{tabular} & gfc & $\mathrm{rg}$ & bde & gfc & $\mathrm{rg}$ & \begin{tabular}{|l|} 
bfg \\
\end{tabular} & bdc & rg & $\mathrm{gg}$ & $\mathrm{fe}$ & $\operatorname{gdc}$ \\
\hline 10 & 2 & 2 & 24 & & 539 & e & gfc & eda & cre & gfc & efc & erg & bde & gfc & $\mathrm{rg}$ & bde & gfc & $\mathrm{rg}$ & \begin{tabular}{|l|} 
bfg \\
\end{tabular} & bdc & erg & $\mathrm{fg}$ & $\mathrm{fe}$ & $\mathrm{gd}$ \\
\hline 11 & 2 & 5 & 79 & & 99 & $\mathrm{fe}$ & gfc & eda & $\mathrm{re}$ & gfc & efc & erg & bde & gfc & $\mathrm{rg}$ & bde & gfc & $\mathrm{rg}$ & $\mathrm{fg}$ & $\mathrm{dc}$ & efa & $\mathrm{rg}$ & fe & $\mathrm{gd}$ \\
\hline 12 & 2 & 14 & 54 & & 5 & $\mathrm{e}$ & $\mathrm{gfc}$ & eda & re & gfc & efc & erg & bde & gfc & $\operatorname{rg}$ & bfg & bdc & rg & $\mathrm{gg}$ & $\mathrm{dc}$ & ia & g & $\mathrm{fe}$ & $\mathrm{gd}$ \\
\hline 13 & 2 & 14 & 79 & & 298 & $\mathrm{fe}$ & gfc & eda & $\mathrm{e}$ & gfc & efc & erg & de & gfc & rg & \begin{tabular}{|l|} 
bfg \\
\end{tabular} & $\mathrm{dc}$ & rg & $\mathrm{g}$ & $\mathrm{fe}$ & ga & $g$ & $\mathrm{fe}$ & $\mathrm{gdc}$ \\
\hline 14 & 2 & 15 & 39 & & 35 & re & gfc & eda & re & gfc & efc & erg & de & gfc & $\mathrm{gg}$ & $\mathrm{g}$ & ic & erg & g| & $\mathrm{fe}$ & da & $\mathrm{crg}$ & $\mathrm{fe}$ & $\mathrm{gd}$ \\
\hline 15 & 2 & 18 & 24 & & 40 & $\mathrm{re}$ & gfc & efc & $\mathrm{rg}$ & bdc & efc & erg & et & gfc & $\mathrm{gg}$ & bfg & $\mathrm{dc}$ & erg & bfg & fe & $\mathrm{a}$ & $r g$ & $\mathrm{fe}$ & $\mathrm{gd}$ \\
\hline 16 & 2 & 20 & 64 & & 65 & $\mathrm{re}$ & gfc & efc & rg & bdc & efc & erg & bde & gfc & $\mathrm{gg}$ & bfg & ic & efa & crg & fe & ata & crg & $\mathrm{fe}$ & $\operatorname{gdc}$ \\
\hline 17 & 3 & 1 & 39 & & 33 & re & $\mathrm{gfc}$ & efc & erg & bdc & efc & erg & bde & $\mathrm{gfc}$ & rg & bfg & $\mathrm{dc}$ & efa & g) & $\mathrm{fe}$ & a & crg & $\mathrm{fe}$ & g16 \\
\hline 18 & 3 & 5 & 34 & & & cre & gfc & efc & erg & bdc & efc & erg & bfg & bdc & $\mathrm{rg}$ & b & dc & $a$ & g & $\mathrm{fe}$ & gda & $\mathrm{crg}$ & $\mathrm{fe}$ & gfe \\
\hline 19 & 3 & 5 & 59 & & 4 & re & gfc & efc & erg & bdc & efc & erg & bfg & $\mathrm{dc}$ & $\mathrm{rg}$ & b & $\mathrm{fe}$ & $\mathrm{da}$ & $\mathrm{crg}$ & $\mathrm{fe}$ & gda & $\mathrm{g}$ & $\mathrm{fe}$ & gfe \\
\hline 20 & 3 & 5 & 79 & & 329 & $\mathrm{re}$ & gfc & efc & $\mathrm{gg}$ & bdc & efc & $\mathrm{rg}$ & b & $\mathrm{Ac}$ & rg & bfg & fe & gda & 10 & fe & gf & $1 \mathrm{a}$ & $\mathrm{re}$ & gfe \\
\hline 21 & 3 & 9 & 04 & & & $\mathrm{rg}$ & $\mathrm{dc}$ & efc & $\mathrm{gg}$ & bdc & efc & $\mathrm{rg}$ & $\mathrm{b}$ & bdc & $\mathrm{rg}$ & bfg & fe & gda| & crg & $\mathrm{fe}$ & gf & eda & e & $\mathrm{gff}$ \\
\hline 22 & 3 & 9 & 29 & ,709 & 535 & erg & bdc & efc & erg & bfe & gdc & $\mathrm{rg}$ & \begin{tabular}{|l|l|} 
bfg \\
\end{tabular} & bdc & $\mathrm{rg}$ & bfg & $\mathrm{fe}$ & gda & g & $\mathrm{fe}$ & gf & eda & e & gfe \\
\hline 23 & 3 & 11 & 14 & & 003 & erg & $\mathrm{dc}$ & efc & $\mathrm{rg}$ & bfe & \begin{tabular}{|l|}
$\mathrm{gdc}$ \\
\end{tabular} & $\mathrm{rg}$ & \begin{tabular}{|l|l|} 
bfg \\
\end{tabular} & bdc & efa & $\mathrm{crg}$ & $\mathrm{fe}$ & gda & $\operatorname{crg}$ & $\mathrm{fe}$ & gf & eda & cre & gfe \\
\hline 24 & 3 & 20 & 539 & & 5 & erg & $\mathrm{dc}$ & efc & $\mathrm{rg}$ & bfe & gdc & $\mathrm{rg}$ & \begin{tabular}{|l|l|} 
bfg \\
\end{tabular} & bfe & gda & \begin{tabular}{|l|} 
crg \\
\end{tabular} & $\mathrm{fe}$ & gda & $\lg$ & fe & gfc & eda & re & gff \\
\hline 25 & 3 & 20 & 564 & 9,924 & 534 & erg & $\mathrm{dc}$ & efc & $\mathrm{rg}$ & bfe & gdc & $\mathrm{rg}$ & \begin{tabular}{|l|} 
bfg \\
\end{tabular} & re & gda & crg & $\mathrm{fe}$ & $\mathrm{gfc}$ & eda & re & $\mathrm{gfc}$ & eda & re & $\mathrm{gff}$ \\
\hline 26 & 3 & 22 & 774 & 1 & 99 & erg & $\mathrm{dc}$ & efc & $\mathrm{rg}$ & bfe & gdc & $\mathrm{rg}$ & bfs & $\mathrm{fe}$ & gda & \begin{tabular}{|c|}
$\mathrm{crg}$ \\
\end{tabular} & $\mathrm{fe}$ & gfc & eda & re & $\mathrm{g}$ & efc & $\mathrm{rg}$ & bd \\
\hline 27 & 4 & ( & 99 & & 535 & erg & bfe & $g d c$ & $\mathrm{rg}$ & bfe & gdc & $\mathrm{rg}$ & bfg & bfe & gda & crg & $\mathrm{fe}$ & $\mathrm{gfc}$ & eda & re & gfc & $\mathrm{efc}$ & $t$ & $\mathrm{bd}$ \\
\hline 28 & 4 & 2 & 24 & 1 & 03 & erg & bfe & gdc & $\mathrm{rg}$ & bfe & gdc & efa & crg & bfe & gda & g & $\mathrm{fe}$ & gfc & eda & $\mathrm{re}$ & gfc & efc & erg & $\mathrm{bd}$ \\
\hline 29 & 4 & 11 & 19 & 1 & & erg & bfe & gdc & $\mathrm{gg}$ & bfe & gfe & $\mathrm{gda}$ & crg & bfe & gda & crg & bfe & $\mathrm{gfc}$ & eda & cre & $\mathrm{gfc}$ & $\mathrm{efc}$ & erg & $\mathrm{bd}$ \\
\hline 30 & 4 & 11 & 14 & 1 & 535 & erg & bfe & gdc & $\mathrm{gg}$ & bfe & gfe & gda & crg & bfe & gfc & eda & re & gfc & eda & cre & gfc & efc & erg & bd \\
\hline 31 & 4 & 14 & 79 & & 833 & erg & bfe & $g d c$ & $\mathrm{~g}$ & bfe & \begin{tabular}{|l|l|} 
gfe \\
\end{tabular} & gda & crg & bfe & gfc & ed & re & gfc & efc & erg & $\mathrm{bdc}$ & efc & 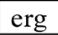 & $b d$ \\
\hline 32 & 4 & 18 & 24 & & 505 & erg & bfe & gdc & $\mathrm{fa}$ & cre & \begin{tabular}{|l|l|} 
gfe \\
\end{tabular} & gda & crg & bfe & gfc & $\mathrm{ec}$ & $\mathrm{re}$ & gf & efc & $\mathrm{rg}$ & $b d c$ & $\mathrm{ffc}$ & 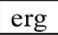 & $b d$ \\
\hline 33 & 5 & 1 & 39 & & 298 & erg & bfe & gdc & fa & cre & gfe & gda & crg & bfe & gfc & es & $\mathrm{re}$ & gf & efc & $\mathrm{rg}$ & bdc & $\mathrm{fc}$ & rg & $f \underline{x}$ \\
\hline 34 & 5 & 2 & 9) & & & erg & bfe & gfe & da & cre & \begin{tabular}{|l|l|} 
gfe \\
\end{tabular} & gda & crg & bfe & gfc & es & re & gf & efc & $\mathrm{rg}$ & bdc & fc & $\mathrm{rg}$ & bfg \\
\hline 35 & 5 & 2 & 4 & & 35 & erg & bfe & gfe & gda & cre & \begin{tabular}{|l|l|} 
gfe \\
\end{tabular} & gfc & ed & cre & gfc & $\mathrm{ec}$ & cre & gf & efc & $\mathrm{rg}$ & $b d c$ & fc & rg & $\mathrm{bfg}$ \\
\hline 36 & 5 & 5 & 9 & & 4 & $\mathrm{~g}$ & bfe & gfe & gda & cre & gfe & gfc & eda & $\mathrm{e}$ & gfc & efc & erg & $\mathrm{bdc}$ & efc & $\mathrm{rg}$ & $b d c$ & $\mathrm{fc}$ & $\mathrm{rg}$ & bfg \\
\hline 37 & 5 & 5 & 79 & & 29 & erg & bfe & gfe & gda & cre & \begin{tabular}{|l|l|} 
gfe \\
\end{tabular} & gfc & ec & cre & gfc & efc & erg & $\mathrm{bdc}$ & $\mathrm{fc}$ & $\mathrm{rg}$ & bfe & $\mathrm{Ac}$ & $\mathrm{rg}$ & bfg \\
\hline 38 & 5 & 9 & 44 & & & efa & cre & gfe & gda & cre & \begin{tabular}{|l|l|} 
gfe \\
\end{tabular} & $\mathrm{gfc}$ & eda & cre & gfc & efc & erg & bdc & efc & erg & bfe & $\mathrm{dc}$ & $\mathrm{rg}$ & bfg \\
\hline 39 & 5 & 9 & 29 & & 399 & efa & cre & gfe & gfc & erg & bde & gfc & ed & cre & gfc & efc & erg & $\mathrm{bdc}$ & efc & erg & bfe & $\mathrm{dc}$ & rg & bfg \\
\hline 40 & 5 & 18 & 4 & & 39 & gda & cre & gfe & $\mathrm{gfc}$ & erg & bde & $\mathrm{gfc}$ & ed & cre & gfc & efc & erg & $\mathrm{bdc}$ & efc & erg & fe & $d c$ & $\mathrm{rg}$ & bfg \\
\hline 41 & 5 & 20 & 39 & 1 & & gda & cre & gfe & $\mathrm{gfc}$ & erg & bde & gfc & efc & erg & bdc & $\mathrm{e}$ & erg & bdc & c & erg & bfe & $\mathrm{dc}$ & $\mathrm{rg}$ & bfg \\
\hline 42 & 5 & 20 & 64 & 1 & 34 & gda & cre & gfe & $\mathrm{gfc}$ & erg & bde & gfc & efc & erg & $\mathrm{dc}$ & ef & erg & ft & gdc & erg & bfe & $\mathrm{dc}$ & $\mathrm{rg}$ & bfg \\
\hline 43 & 5 & 22 & 74 & & 99 & gda & cre & gfe & $\mathrm{gfc}$ & erg & bde & gfc & efc & erg & $\mathrm{dc}$ & ef & erg & $\mathrm{fe}$ & gdc & erg & fe & $\mathrm{dc}$ & fa & $\mathrm{crg}$ \\
\hline 44 & 6 & 4 & 9 & & 05 & gfc & $\mathrm{rg}$ & bde & $\mathrm{gfc}$ & erg & de & gfc & efc & erg & $\mathrm{bdc}$ & e & $\mathrm{rg}$ & bfe & $\mathrm{gdc}$ & $\mathrm{rg}$ & $\mathrm{fe}$ & $\mathrm{dc}$ & $\mathrm{fa}$ & $\mathrm{crg}$ \\
\hline 45 & 6 & 7 & 4 & & 33 & gfc & erg & le & $\mathrm{gfc}$ & erg & bde & gfc & efc & erg & bdc & efc & erg & bfe & $\mathrm{gdc}$ & $\mathrm{rg}$ & bfe & gfe & da & crg \\
\hline 46 & 6 & & & & 5 & gfc & erg & bde & $\mathrm{gfc}$ & erg & bfg & $\mathrm{dc}$ & efc & erg & I & efc & $\mathrm{rg}$ & bfe & gdc & $\mathrm{rg}$ & bfe & gfe & $\mathrm{da}$ & crg \\
\hline 47 & 6 & 11 & & & 35 & gfc & $\mathrm{rg}$ & bde & gfc & erg & bfg & $\mathrm{dc}$ & efc & erg & bfe & gdc & $\operatorname{cg}$ & bfe & \begin{tabular}{|l|}
$\mathrm{gdc}$ \\
\end{tabular} & $\mathrm{rg}$ & bfe & gfe & $\mathrm{da}$ & crg \\
\hline 48 & 6 & 14 & 79 & & 03 & gfc & erg & bde & $\mathrm{gfc}$ & erg & bfg & $\mathrm{dc}$ & efc & erg & bfe & \begin{tabular}{|l|} 
gdc \\
\end{tabular} & rg & bfe & gdc & \begin{tabular}{|l|} 
efa \\
\end{tabular} & $\mathrm{cr}$ & $\mathrm{fe}$ & da & $\mathrm{rg}$ \\
\hline 49 & \begin{tabular}{l|l}
6 \\
\end{tabular} & 22 & 54 & 1 & t & gfc & erg & bde & gfc & erg & bfg & bdc & efc & erg & bfe & $\mathrm{gdc}$ & $\operatorname{rg}$ & bfe & gfe & $\mathrm{da}$ & cre & $\mathrm{fe}$ & da & $\mathrm{crg}$ \\
\hline 50 & \begin{tabular}{l|l}
6 \\
\end{tabular} & 22 & 74 & 1 & 29 & $\mathrm{fc}$ & erg & 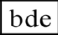 & gfc & erg & bfg & $\mathrm{dc}$ & efc & erg & $\mathrm{fe}$ & $\mathrm{gdc}$ & $\mathrm{rg}$ & $\mathrm{bfe}$ & gfe & gda & cre & $\mathrm{fe}$ & $\mathrm{fc}$ & eda \\
\hline 51 & $\begin{array}{ll}0 \\
\end{array}$ & 7 & & & 71 & gfc & erg & bfg & bdc & erg & bfg & $\mathrm{dc}$ & efc & erg & $\mathrm{fe}$ & $\mathrm{gdc}$ & $\mathrm{rg}$ & bfe & gf & gda & cre & gfe & $\mathrm{fc}$ & da \\
\hline 52 & 0 & 2 & & & 35 & gfc & erg & bf & $\mathrm{bdc}$ & erg & bfg & $\mathrm{fe}$ & gdc & erg & $\mathrm{fe}$ & $\mathrm{gdc}$ & rg & b & gf & $\mathrm{da}$ & $\mathrm{re}$ & gfe & $\mathrm{fc}$ & eda \\
\hline 53 & 0 & 5 & & & 4 & gfc & erg & $\mathrm{bf}$ & bdc & erg & bfg & $\mathrm{fe}$ & $\mathrm{gdc}$ & erg & $\mathrm{fe}$ & $\mathrm{gdc}$ & efa & cre & gf & $\mathrm{da}$ & $\mathrm{re}$ & ee & fc & da \\
\hline 54 & 0 & 5 & & 9 & & gfc & erg & $\mathrm{bft}$ & $\mathrm{dc}$ & erg & bfg & $\mathrm{fe}$ & gdc & erg & bfe & $\mathrm{gd}$ & efa & cre & gf & gfc & erg & $\mathrm{de}$ & $\mathrm{fc}$ & eda \\
\hline 55 & 0 & 9 & 229 & 9 & 565 & gfc & erg & $\mathrm{bfg}$ & $\mathrm{dc}$ & efa & crg & $\mathrm{fe}$ & $\mathrm{gdc}$ & erg & bfe & gdc & efa & cre & gfe & gfc & erg & de & $\mathrm{fc}$ & $\mathrm{da}$ \\
\hline 56 & 0 & 14 & & 27 & & gfc & erg & bfg & bdc & efa & crg & bfe & gdc & erg & bfe & gfe & gda & cre & gfe & gfc & erg & de & $\mathrm{ffc}$ & eda \\
\hline 57 & 0 & 16 & 007 & 1 & 299 & gfc & erg & bfg & bdc & efa & crg & bfe & $\operatorname{gdc}$ & erg & bfe & gfe & gda & cre & gfe & gfc & erg & de & gfc & $\mathrm{efc}$ \\
\hline 58 & 0 & 18 & & 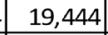 & 4 & bdc & $\mathrm{rg}$ & $\mathrm{bfg}$ & bdc & efa & crg & bfe & gdc & erg & bfe & gf & gda & cre & gf & gfc & erg & Ief & gfc & efc \\
\hline 59 & 0 & 18 & & 1 & 535 & bdc & erg & $\mathrm{bfg}$ & bfe & $\mathrm{gda}$ & crg & bfe & $\mathrm{gd}$ & erg & bfe & gfe & gda & $\mathrm{cr}$ & gf & gfc & er & $\pi$ & $f \mathrm{fc}$ & efc \\
\hline 60 & 0 & 20 & 5 & & 5 & bdc & erg & bfg & bfe & gd: & crg & bfe & $\mathrm{gd}$ & efa & cre & gfe & gda & $\mathrm{cr}$ & \begin{tabular}{|l|} 
gfe \\
\end{tabular} & gfc & erg & de & gfc & efc \\
\hline$u_{1}$ & 0 & 20 & 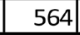 & 2,164 & 1 & bdc & erg & bfg & bfe & gda & crg & bfe & $\mathrm{gdc}$ & efa & cre & gfe & gfe & erg & bde & gfc & erg & ode & $\mathrm{gfc}$ & efe \\
\hline
\end{tabular}


use will increase seven-fold for one who studies the calculation of the calendar at a deeper level. It will make it possible to solve many problems that can be solved with great difficulty using the table of four gates. (Part of this table first appeared in the writings of Al-khwarizmiin in the year 824 [7].

Reprinted: SIES, pp. 661-665. With this table one can find the year code of a particular year based on the borders of the new moon of the year without the necessity of knowing the new moon of the previous year and without considering the four deferments).

The example presented below is an application that illustrates the prediction of Bornstein.

\subsection{Presentation of the Conundrum}

We will present the problem with an example which we will use as a test case.

The years 5779 and 5080 have the year codes of bfg and bfe respectively. If we examine a list of all year codes, we see that the combination of these two-year codes appear many times with various intervals between them. In Table 4, we see some of the years in which this combination appears, the number of whole 19 year cycles that have elapsed, the number of the year in the cycle and the interval between these occurrences.

If one examines the intervals of the occurrence of this pair of year codes one will see (in Table 4) the following arithmetic relationships:

$$
\begin{aligned}
& 27+71=98 \\
& 27+51=78
\end{aligned}
$$

We must answer the following questions:

Are these all the possible intervals?

What is the significance of the arithmetic relationships between the intervals?

\begin{tabular}{|c|c|c|c|c|c|c|}
\hline $\begin{array}{c}\text { Occurrence } \\
\text { number }\end{array}$ & $\begin{array}{c}\text { First year } \\
\text { of pair }\end{array}$ & $\begin{array}{l}\text { Number of } \\
\text { cycles that } \\
\text { have elapsed }\end{array}$ & $\begin{array}{l}\text { Number } \\
\text { of year in } \\
\text { the cycle }\end{array}$ & Interval & $\begin{array}{c}\text { New moon of } \\
\text { New Years of the } \\
\text { first year of the cycle }\end{array}$ & $\begin{array}{l}\text { Row in the } \\
\text { table of } 61 \\
\text { headings }\end{array}$ \\
\hline-5 & 5532 & 291 & 3 & & 23,229 & 61 \\
\hline-4 & 5603 & 294 & 17 & 71 & 50,934 & 8 \\
\hline-3 & 5630 & 296 & 6 & 27 & 8924 & 54 \\
\hline-2 & 5681 & 298 & 0 & 51 & 148,354 & 39 \\
\hline-1 & 5708 & 300 & 8 & 27 & 106,344 & 27 \\
\hline 0 & 5779 & 304 & 3 & 71 & 22,324 & 61 \\
\hline 1 & 5877 & 309 & 6 & 98 & 8019 & 54 \\
\hline 2 & 5955 & 313 & 8 & 78 & 105,439 & 27 \\
\hline 3 & 6026 & 317 & 3 & 71 & 21,419 & 59 \\
\hline 4 & 6124 & 322 & 6 & 98 & 7114 & 54 \\
\hline 5 & 6202 & 326 & 8 & 78 & 104,534 & 27 \\
\hline
\end{tabular}

Table 4. Table of the occurrence of paired year codes bfg and bfe. 
We are interested in finding a method for identifying the intervals between the occurrences of any pair of year codes. In addition, we want to understand the attributes of these intervals and the arithmetic relationships between them.

\subsection{A Solution}

Using the amended table of sixty-one headings (which represents the cycling of the year codes in the Jewish calendar), we will proceed as follows:

a) We will prepare a highlighted table, marking all the paired year codes that we are studying.

b) Open the rows as necessary.

c) List the ranges for the first year of the cycle for all the relevant rows (from and to (non-inclusive).

d) Characterize the equations of the intervals.

e) Preparation of a table that includes all these ranges (for each year group) in which we will sequentially add the remainder of a cycle to each previous range.

f) Create a diagram of all the groups with arrows between the years listing the intervals.

g) Analysis of the diagram.

\section{1) The preparation of a highlighted table}

The year code bfg (as in the year 5779) can only appear in a leap year. Therefore, all the paired year codes bfg - bfe can only be in the paired years: 3 - 4, 6 - 7, 8 - 9, 11 - 12, 14 - 15, 17 - 18, 19 - 1).

Table 5 is the table of sixty-one headings in which we have marked all the pairs bfg - bfe.

\section{2) Open the rows as necessary}

In as much as the pairs of year codes include the years 19 and then 1 (in the following 19-year cycle), we must calculate the interval of the possible times of the new moon of the following 19-year cycle.

In the 19th year of the cycles, the year code bfg appears in rows 33 until 42 (including). In the first year of the cycles the year code bfe appears in rows 4 until 13 inclusive. From these rows we must chose the new moon intervals that will match the year code bfg (of year 19) with the year code bfe of the year 1).

a) We choose the first row in which the year code for year 1 is bfe (the $4^{\text {th }}$ row). From the beginning of the interval of new moons in this row $(35,844)$ we subtract the remainder of a cycle $(69,715)$ and we then check in which row this new moon appears. This new moon falls in the range of row 39 . Therefore, we must split row 39 into two rows. The first of these two rows will begin with the same new moon as the original row and end at 147,569 (not including). This first line will not be followed by a year whose code is bfe. The second row will begin with 147,569 and the following year (year 1 will have a year code of bfe.

$$
(35,844-69,715)(\bmod 181,440)=147,569 \text { parts }
$$

b) In a similar way, we will deal with the last row that ends (year 19) with the year code bfg (row 42). To do this we will choose the new moon of the first year 
Table 5. Extended sixty-one headings.

\begin{tabular}{|c|c|c|c|c|c|c|c|c|c|c|c|c|c|c|c|c|c|c|c|c|c|c|c|c|}
\hline \multicolumn{25}{|c|}{ Table of 61 headings - Actual limits } \\
\hline \multirow[b]{2}{*}{$\mathrm{n}$} & \multicolumn{4}{|c|}{ Bord } & \multirow[b]{2}{*}{ occurences } & & & & & & & & & Year i & $\mathrm{n}$ the & cycle & & & & & & & & \\
\hline & daynd & & part & parts & & 1 & 2 & 3 & 4 & 5 & 6 & 7 & 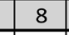 & 5 & 10 & 11 & 12 & 13 & 14 & 15 & 16 & 17 & 18 & 19 \\
\hline 1 & 1 & 0 & 409 & 26,329 & 1,065 & bdc & efa & $\mathrm{crg}$ & bfe & gda & $\mathrm{crg}$ & bfe & $\mathrm{gdc}$ & efa & cre & gfe & gfc & erg & bde & $\mathrm{gfc}$ & erg & bde & $\mathrm{gfc}$ & efc \\
\hline 2 & 1 & & 334 & 654 & 540 & bdc & efa & $\mathrm{crg}$ & bfe & gda & $\mathrm{crg}$ & bfe & gfe & gda & cre & gfe & gfc & erg & bde & gfc & erg & bde & gfc & efo \\
\hline 3 & 1 & & 874 & 354 & 298 & bdc & efa & $\mathrm{crg}$ & bfe & gda & crg & bfe & gfe & $\mathrm{gda}$ & cre & gfe & gfc & erg & bde & gfc & erg & bfg & bdc & efc \\
\hline 4 & 1 & 9 & 204 & 844 & & bfe & gda & crg & bfe & gda & $\mathrm{crg}$ & bfe & gfe & $\mathrm{gda}$ & cre & gfe & gfc & erg & bde & gfc & erg & bfg & bdc & efc \\
\hline 5 & 1 & 9 & 29 & 5,869 & 535 & bfe & gda & $\mathrm{crg}$ & bfe & gfc & eda & cre & gfe & gda & cre & gfe & gfc & erg & bde & gfc & erg & bfg & bdc & efc \\
\hline 6 & 1 & 11 & 744 & 544 & 833 & bfe & gda & $\mathrm{crg}$ & bfe & gfc & eda & cre & gfe & gfc & erg & bde & gfc & erg & bde & gfc & erg & bfg & $\mathrm{bdc}$ & efc \\
\hline & 1 & 15 & 589 & 709 & 1,605 & bfe & $\mathrm{gda}$ & crg & bfe & gfc & eda & cre & $\mathrm{gfe}$ & gfc & erg & bde & gfc & erg & bde & gfc & erg & $\mathrm{bfg}$ & $\mathrm{dc}$ & efc \\
\hline 7 & 1 & 22 & 1,054 & 0,734 & & bfe & gda & crg & bfe & gfc & eda & cre & gfe & $\mathrm{gfc}$ & erg & bde & gfc & erg & bfg & bdc & erg & bfg & $\mathrm{dc}$ & efc \\
\hline 8 & 1 & 22 & 1,074 & 0,754 & 299 & bfe & gda & crg & bfe & $\mathrm{gfc}$ & eda & cre & gfe & gfc & erg & bde & gfc & erg & $\mathrm{bfg}$ & bdc & erg & bfg & bfe & $\mathrm{gdc}$ \\
\hline 9 & 2 & 0 & 409 & 2,249 & 535 & bfe & gfc & eda & cre & gfc & eda & cre & $\mathrm{gfe}$ & gfc & erg & bde & gfc & erg & bfg & bdc & erg & bfg & bfe & $\mathrm{gdc}$ \\
\hline 10 & 2 & I & 924 & 924 & 539 & bfe & gfc & eda & cre & $\mathrm{gfc}$ & efc & erg & bde & gfc & erg & bde & gfc & $\mathrm{rg}$ & $\mathrm{bfg}$ & bdc & erg & bfg & bfe & gdc \\
\hline 11 & 2 & 5 & 379 & 619 & 1,899 & bfe & gfc & eda & cre & $\mathrm{gfc}$ & efc & erg & bde & $\mathrm{gfc}$ & erg & bde & gfc & erg & bfg & bdc & efa & crg & bfe & $\mathrm{gdc}$ \\
\hline 12 & 2 & 4 & 154 & 114 & & bfe & gfc & eda & cre & gfc & efc & erg & bde & gfc & erg & bfg & bdc & erg & bfg & bdc & efa & crg & bfe & $\mathrm{gdc}$ \\
\hline 13 & 2 & 14 & 1 & 139 & 298 & bfe & gfc & eda & cre & $\mathrm{gfc}$ & efc & erg & bde & $\mathrm{gfc}$ & erg & bfg & bdc & erg & $\mathrm{bfg}$ & bfe & gda & crg & bfe & gdc \\
\hline 14 & 2 & 15 & 89 & 529 & 535 & cre & gfc & eda & cre & gfc & efc & erg & bde & $\mathrm{gfc}$ & erg & bfg & bdc & erg & $\mathrm{bfg}$ & bfe & $\mathrm{gda}$ & crg & bfe & $\mathrm{gd}$ \\
\hline 15 & 2 & 18 & 24 & 304 & 540 & cre & gfc & efc & erg & bdc & efc & erg & bde & gfc & erg & bfg & bdc & $\mathrm{rg}$ & $\mathrm{bfg}$ & bfe & gda & crg & bfe & $\mathrm{gd}$ \\
\hline 16 & 2 & 20 & 5 & 04 & 065 & cre & gfc & efc & erg & bdc & efc & erg & bde & $\mathrm{gfc}$ & erg & bfg & $\mathrm{bdc}$ & efa & crg & bfe & $\mathrm{gda}$ & crg & bfe & $\mathrm{gdc}$ \\
\hline 17 & 3 & & 4 & 329 & 833 & cre & $\mathrm{gfc}$ & efc & erg & bdc & efc & erg & bde & $\mathrm{gfc}$ & erg & bfg & $\mathrm{bdc}$ & efa & crg & bfe & gda & crg & $\mathrm{fe}$ & gfe \\
\hline 18 & 3 & 5 & 334 & 494 & & cre & gfc & efc & erg & bdc & efc & erg & bfg & bdc & erg & bfg & bdc & efa & crg & bfe & gda & crg & bfe & gfe \\
\hline 19 & 3 & 5 & 359 & 519 & & cre & gfc & efc & erg & bdc & efc & erg & bfg & bdc & erg & bfg & bfe & gda & crg & bfe & gda & crg & bfe & gfe \\
\hline 20 & 3 & 5 & 79 & 539 & 829 & cre & gfc & efc & erg & bdc & efc & erg & bfg & $b d c$ & erg & bfg & bfe & gda & $\mathrm{crg}$ & bfe & gfc & eda & cre & gfe \\
\hline 21 & 3 & 9 & 04 & 684 & & erg & bdc & efc & erg & bdc & efc & erg & bfg & $\mathrm{bdc}$ & erg & bfg & bfe & gda & crg & bfe & gfc & eda & cre & gfe \\
\hline 22 & 3 & 9 & 229 & 709 & 535 & erg & bdc & efc & erg & bfe & $\mathrm{gdc}$ & erg & bfg & $\mathrm{bdc}$ & erg & bfg & bfe & gda & crg & bfe & gfc & eda & cre & gfe \\
\hline 23 & 3 & 11 & 744 & 384 & 1,903 & erg & bdc & efc & erg & bfe & $g d c$ & erg & bfg & bdc & efa & crg & bfe & gda & crg & bfe & gfc & eda & cre & gfe \\
\hline 24 & 3 & 20 & 539 & 899 & & erg & bdc & efc & erg & bfe & $\mathrm{gdc}$ & erg & bfg & bfe & gda & crg & bfe & gda & $\mathrm{crg}$ & bfe & gfc & eda & cre & gfe \\
\hline 25 & 3 & 20 & 564 & 924 & 534 & erg & bdc & efc & erg & bfe & $\mathrm{gdc}$ & erg & bfg & bfe & gda & $\mathrm{crg}$ & bfe & gfc & eda & cre & gfc & eda & cre & $\mathrm{gfe}$ \\
\hline 26 & 3 & 22 & 1,074 & 594 & 299 & erg & bdc & efc & erg & bfe & $g d c$ & erg & bfg & bfe & gda & $\operatorname{crg}$ & bfe & gfc & eda & cre & gfc & efc & erg & $\mathrm{bdc}$ \\
\hline 27 & 4 & & 409 & 089 & 535 & erg & bfe & $\mathrm{gdc}$ & erg & bfe & $\mathrm{gdc}$ & erg & bfg & bfe & gda & crg & bfe & gfc & eda & cre & $\mathrm{gfc}$ & $\mathrm{Ic}$ & erg & $\mathrm{bde}$ \\
\hline 28 & 4 & 2 & 24 & 6,764 & 1,903 & erg & bfe & $g d c$ & erg & bfe & $g d c$ & efa & $\mathrm{crg}$ & bfe & gda & crg & bfe & gfc & eda & cre & gfc & efc & erg & $\mathrm{bdc}$ \\
\hline 29 & 4 & 11 & 19 & 279 & & erg & bfe & $\mathrm{gdc}$ & erg & bfe & gfe & gda & $\mathrm{a} \operatorname{crg}$ & bfe & gda & crg & bfe & gfc & eda & cre & gfc & $\mathrm{Ic}$ & erg & bde \\
\hline 30 & 4 & $11]$ & 744 & 304 & 535 & erg & bfe & $\mathrm{gdc}$ & erg & bfe & gfe & gda & $\mathrm{a} \operatorname{crg}$ & bfe & $\mathrm{gfc}$ & eda & cre & gfc & eda & cre & gfc & efc & erg & $\mathrm{bd}$ \\
\hline 31 & 4 & 4 & 99 & & 833 & erg & $\underline{b f}$ & $\mathrm{gdc}$ & $\mathrm{rg}$ & bfe & gfe & gda & $\mathrm{a} \operatorname{crg}$ & bfe & gfc & eda & cre & gfc & efc & erg & $\mathrm{bdc}$ & $\mathrm{fc}$ & erg & $\mathrm{bd}$ \\
\hline 32 & 4 & 18 & 4 & & 505 & erg & bfe & $\mathrm{gdc}$ & $\mathrm{fa}$ & cre & gfe & gda & $\mathrm{a} \operatorname{crg}$ & bfe & gfc & eda & cre & gfc & efc & erg & bdc & $\mathrm{fc}$ & erg & bde \\
\hline 33 & 5 & & 489 & & 298 & erg & bfe & $g d c$ & efa & cre & gfe & gda & $\mathrm{a} \operatorname{crg}$ & bfe & gfc & eda & cre & gfc & efc & erg & bdc & efc & rg & bfg \\
\hline 34 & 5 & & 899 & 659 & & erg & bfe & gfe & gda & cre & gfe & gda & $\mathrm{a} \operatorname{crg}$ & bfe & gfc & eda & cre & gfc & efc & erg & bdc & efc & erg & $\mathrm{bfg}$ \\
\hline 35 & 5 & 2 & 4 & 684 & 535 & erg & bfe & gfe & gda & cre & gfe & gfc & c eda & a cre & $\mathrm{gfc}$ & eda & cre & gfc & efc & erg & bdc & efc & erg & bfg \\
\hline 36 & 5 & & 359 & 359 & & erg & bfe & $\mathrm{gfe}$ & gda & cre & gfe & gfc & $c$ eda & a cre & gfc & efc & erg & bdc & efc & erg & bdc & efc & erg & bfg \\
\hline 37 & 5 & & 379 & ,379 & 829 & erg & bfe & gfe & gda & cre & gfe & gfc & c eda & $\begin{array}{lll}a \\
\end{array}$ & gfc & efc & erg & bdc & efc & erg & bfe & gdc & erg & bfg \\
\hline 38 & 5 & 9 & 204 & 524 & & efa & cre & gfe & gda & cre & gfe & gfc & $c$ eda & a cre & gfc & efc & erg & $\mathrm{dc}$ & efe & erg & $\mathrm{fe}$ & $\mathrm{gdc}$ & erg & bfg \\
\hline 39 & 5 & 9 & 229 &, 549 & 1,604 & efa & cre & gfe & gfc & erg & bde & gfc & $c$ eda & $\begin{array}{ll} \\
\end{array}$ & gfc & efc & erg & $\mathrm{dc}$ & efc & erg & ofe & $\mathrm{gdc}$ & erg & $\mathrm{bfg}$ \\
\hline & 5 & 1 & 689 & 569 & 295 & efa & cre & gfe & gfc & erg & bde & gfc & c eda & a cre & gfc & efc & erg & $b d c$ & efc & erg & $\mathrm{fe}$ & $g d c$ & erg & bfg \\
\hline 40 & 5 & 8 & 4 & 044 & 539 & gda & cre & $\mathrm{gfe}$ & gfc & erg & bde & $\mathrm{gfc}$ & eda & a cre & $\mathrm{gfc}$ & efc & erg & 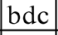 & $\mathrm{e}$ & erg & $\mathrm{fe}$ & Ic & erg & bfg \\
\hline 41 & 5 & 20 & 9 & & & gda & cre & gfe & fc & erg & bde & gfc & \begin{tabular}{ll|} 
& efc \\
\end{tabular} & erg & bdc & efc & erg & bdc & efc & erg & bfe & $\mathrm{gdc}$ & erg & bfg \\
\hline 42 & 5 & 20 & 54 & & 534 & gda & cre & gfe & gfc & erg & bde & gfc & \begin{tabular}{ll|}
$c$ & efc \\
\end{tabular} & erg & bdc & efc & erg & bfe & gdc & \begin{tabular}{|l|} 
erg \\
\end{tabular} & fe & $\mathrm{gdc}$ & \begin{tabular}{|l|} 
erg \\
\end{tabular} & bfg \\
\hline 43 & 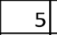 & 22 & 1,074 & & 299 & gda & cre & gfe & gfc & erg & bde & gfc & \begin{tabular}{|l|l|}
$c$ & efc \\
\end{tabular} & erg & $\mathrm{bdc}$ & efc & $\mathrm{rg}$ & bfe & $g d c$ & erg & bfe & $\mathrm{gdc}$ & efa & $r g$ \\
\hline 44 & 6 & 0 & 4 & & 1,605 & gfc & erg & bde & gfc & erg & bde & gfc & \begin{tabular}{ll|} 
& efc \\
\end{tabular} & erg & bdc & efc & $\mathrm{rg}$ & bfe & $\mathrm{gdc}$ & erg & bfe & $\mathrm{gdc}$ & efa & $\mathrm{crg}$ \\
\hline 45 & 6 & & 8 & & 833 & gfc & $1 \mathrm{~s}$ & bde & gfc & $\mathrm{gg}$ & bde & gfc & \begin{tabular}{ll|}
$c$ & efc \\
\end{tabular} & rg & bdc & efc & $\mathrm{rg}$ & bfe & gdc & erg & bfe & gfe & gda & $\mathrm{crg}$ \\
\hline 46 & 6 & 1 & & & & gfc & erg & bde & $\mathrm{gfc}$ & $\mathrm{g}$ & bfg & bdc & \begin{tabular}{l|l|}
$c$ & efc \\
\end{tabular} & $\mathrm{rg}$ & bdc & efc & $\mathrm{rg}$ & bfe & $g d c$ & er & bfe & gfe & gda & crg \\
\hline 47 & 6 & 1 & & 144 & 35 & gfc & erg & bde & gfc & $\mathrm{rg}$ & bfg & bdc & $\begin{array}{c}\mathrm{c} \\
\mathrm{c}\end{array}$ & erg & bfe & $\mathrm{gdc}$ & erg & $\mathrm{fe}$ & $\operatorname{gdc}$ & erg & bfe & gfe & a & crg \\
\hline 48 & 6 & 14 & 9 & 819 & 903 & gfc & erg & bde & gfc & $\mathrm{g}$ & bfg & $\mathrm{bdc}$ & \begin{tabular}{l|l|}
$c$ & efc \\
\end{tabular} & $\mathrm{e}$ & bfe & gdc & erg & $\mathrm{fe}$ & $g d c$ & efa & cre & gfe & gda & 1 \\
\hline 49 & 6 & 22 & 054 &, 334 & & gfc & erg & bde & gfc & erg & bfg & bdc & \begin{tabular}{l|l|}
$c$ & efc \\
\end{tabular} & erg & bfe & gdc & erg & bfe & gfe & gda & cre & gfe & gda & crg \\
\hline 50 & 6 & 22 & 1,074 & 180,354 & 829 & gfc & erg & bde & gfc & erg & $\mathrm{bfg}$ & bdc & \begin{tabular}{c|c|}
$c$ & efc \\
\end{tabular} & erg & bfe & $\mathrm{gdc}$ & erg & bfe & gfe & gda & cre & gfe & gfc & eda \\
\hline 51 & 0 & 2 & 895 & 059 & & gfc & erg & bfg & bdc & erg & bfg & bdc & $\begin{array}{c}c \\
c\end{array}$ & 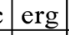 & bfe & $\mathrm{gdc}$ & erg & bfe & gfe & gda & cre & gfe & $\mathrm{gfc}$ & ed \\
\hline 52 & 0 & & 924 & 34 & 535 & $\mathrm{gfc}$ & erg & bfg & bdc & erg & $\mathrm{bfg}$ & bfe & $\mathrm{gdc}$ & \begin{tabular}{l|l|}
$c$ & erg \\
\end{tabular} & bfe & gdc & erg & bfe & gfe & gda & cre & gfe & $\mathrm{gfc}$ & eda \\
\hline 53 & 0 & 5 & 355 & 599 & & gfc & erg & bfg & bdc & erg & $\mathrm{bfg}$ & bfe & $\mathrm{gdc}$ & c erg & bfe & gdc & efa & cre & gfe & $\mathrm{gda}$ & cre & gfe & $\mathrm{gfc}$ & eda \\
\hline 54 & 0 & 5 & 376 & 779| & 834 & gfc & erg & $\mathrm{bfg}$ & bdc & erg & $\mathrm{bfg}$ & bfe & $\mathrm{gdc}$ & cerg & bfe & gdc & efa & cre & gfe & $\mathrm{gfc}$ & erg & bde & gfc & eda \\
\hline 55 & 0 & 9 & 225 & 49 & 1,065 & gfc & erg & bfg & bdc & efa & $\mathrm{crg}$ & bfe & $\mathrm{gdc}$ & c erg & bfe & gdc & efa & cre & gfe & gfc & erg & bde & gfc & ed \\
\hline 56 & 0 & 14 & 154 & 274 & 539 & gfc & erg & bfg & bdc & efa & crg & bfe & $\mathrm{gdc}$ & $\begin{array}{l}\mathrm{c} \text { erg } \\
\end{array}$ & bfe & gfe & gda & cre & gfe & gfc & erg & bde & gfc & edc \\
\hline 57 & 0 & 16 & 689 & 669] & 295 & gfc & erg & bfg & bdc & efa & $\mathrm{crg}$ & bfe & $\mathrm{gdc}$ & \begin{tabular}{c|c|} 
& erg \\
\end{tabular} & bfe & gfe & gda & cre & gfe & gfc & erg & bde & gfc & efo \\
\hline 58 & 0 & 18 & & & & bdc & erg & bfg & bdc & efa & $\mathrm{crg}$ & bfe & $\mathrm{gdc}$ & \begin{tabular}{c|c|}
$c$ & erg \\
\end{tabular} & bfe & gfe & gda & cre & gfe & gfc & erg & $\mathrm{de}^{-}$ & gfc & efc \\
\hline 59 & 0 & 18 & & & 535 & bdc & erg & $\mathrm{bfg}$ & bfe & gda & $\mathrm{rg}$ & bfe & $\mathrm{gdc}$ & c & bfe & gfe & gda & $\mathrm{re}$ & gfe & gfc & erg & & fo & $\mathrm{fec}$ \\
\hline 60 & 0 & 20 & & 39 & & bdc & erg & bfg & bfe & gda & $\mathrm{crg}$ & bfe & $\mathrm{gdc}$ & $\mathrm{fa}$ & cre & gfe & gda & cre & gfe & gfc & erg & bde & $\mathrm{gfc}$ & efc \\
\hline 61 & 0 & 20 & & & 33 & & & $\mathrm{fg}$ & bfe & gda & & bfe & $\mathrm{gdc}$ & $\mathrm{c}$ & cre & $\mathrm{fel}$ & $\mathrm{gfc}$ & $\mathrm{rg}$ & $\mathrm{de}$ & $\mathrm{gfc}$ & er & bde & gfc & efc \\
\hline
\end{tabular}


of row 43(154,434) and add the remainder of a 19-year cycle:

$$
(154,434+69,715)(\bmod 181,440)=42,709 \text { parts }
$$

This falls within row 6 and we therefore have to divide row 6 into 2 rows. The first row includes the new moons that the previous year (year 19) was bfg and the second row the year code of the previous year (year 19) was not bfg.

3) List the intervals for the first year of the cycle for all the relevant rows (from and to, non-inclusive)

We will summarize in a table all the intervals for all the years in the cycle that are relevant for the paired year codes we are studying.

Table 6 includes all the intervals of the new moon of the beginning of a 19 -year cycle in which the year code pair bfg-bfe appears. The table is ordered from left to right from the lowest new moon to the highest. The sum of the occurrences of all the intervals listed is equal to 1373 (e.g. year 6 includes rows 52, 53 and 54 for which the occurrences are $535+4+834=1373)$.

\section{4) Characterize the equations of the intervals}

If the new moon of the beginning of a 19-year cycle is within the range of the new moons that are defined for a cycle in which the year code pair appears, we then ask ourselves, after how many 19-year cycles will we enter a new interval of new moons that define cycles in which this pair will appear.

In Figure 1, year $n$ in cycle $x$ includes the year code pair we are studying. The next time this pair will appear will be in year $m$ of cycle $y$.

$20-n=$ the number of years from year $n$ until the end of cycle $\times$ (including $n)$.

$m-1=$ the number of years from the beginning of cycle y until the year $m$ (not including year $\mathrm{m}$ ).

The time between the two mentioned years is defined as $\Delta$

$$
\begin{aligned}
\Delta & =20-n+19 A+m-1 \\
& =19-n+m+19 A \\
& =-n+m+19(A+1)
\end{aligned}
$$

Table 6. List the intervals for the first year of the cycle for all the relevant rows.

\begin{tabular}{ccccccccccccccc}
\hline \multicolumn{2}{c}{ Year 6 } & \multicolumn{2}{c}{ Year 3 } & \multicolumn{2}{c}{ Year 17 } & \multicolumn{2}{c}{ Year 14 } & \multicolumn{2}{c}{ Year 11 } & & Year 8 & Year 19 \\
\hline From & $\begin{array}{c}\text { To } \\
\text { (non incl.) }\end{array}$ & From & $\begin{array}{c}\text { To } \\
\text { (non incl.) }\end{array}$ & From & $\begin{array}{c}\text { To } \\
\text { (non incl.) }\end{array}$ & From & $\begin{array}{c}\text { To } \\
\text { (non incl.) }\end{array}$ & From & $\begin{array}{c}\text { To } \\
\text { (non incl.) }\end{array}$ & From & $\begin{array}{c}\text { To } \\
\text { (non incl.) }\end{array}$ & $\begin{array}{c}\text { From } \\
\text { (non incl.) }\end{array}$ \\
3084 & 9949 & 19,464 & 26,329 & 50,754 & 57,619 & 67,139 & 74,004 & 83,519 & 90,384 & 99,899 & 106,764 & 147,569 & 154,434 \\
\hline
\end{tabular}

Year $n$ in cycle $x$

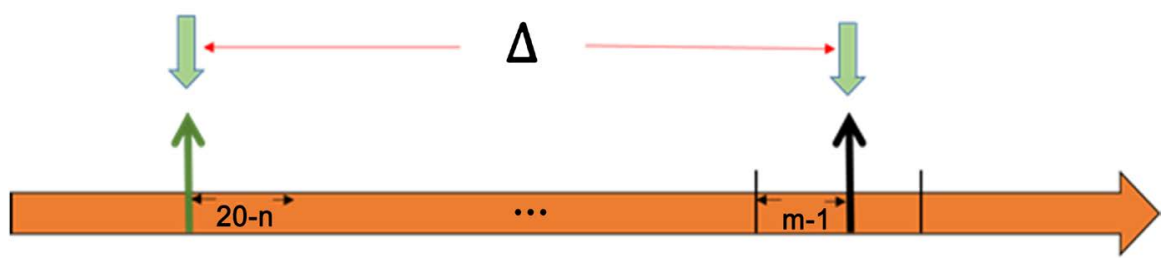

Figure 1. The gap between two events. 
$A=$ number of cycles.

$A \in Z^{+}$.

If we place values of " $A$ " from 0 to 5 in formula 2 for different sets of years we get the results in Table 7. In fact, as will be explained below, only the shaded numbers are in fact possible. The table is only an example of possible combinations and does not represent all possible transitions from one year to another.

5) Preparation of a table that includes all these ranges (for each year group) in which we will sequentially add the remainder of a cycle to each previous range

We will start with one of the years with the paired year codes. We will add to the range of new moons that give this year the remainder of a 19-year cycle $(69,715)$ and we will check if the calculated range falls within a cycle that contains the paired year code. From this range, we will continue in the same way until the calculated range falls in the range of another one of the cycles with a paired year code.

In Figure 2, we see a schematic representation in which we start from year $a_{1}$. After an interval of $\Delta_{1}$ years, we reach year $a_{2}$. After an interval of $\Delta_{2}$ years, we reach year $a_{3}$. When we have exhausted all possibilities for year $a_{1}$ we will begin this process with year $a_{2}$.

\section{Example}

We will demonstrate this method using the paired year codes we have been working with, bfg - bfe.

Starting with the appearance of this pair in the cycles in which it occurs in year 6 (the year we start with is unimportant) we add the remainder of a cycle to

Table 7. The possible values of $\Delta$ for values of $A=0$ until $A=5$.

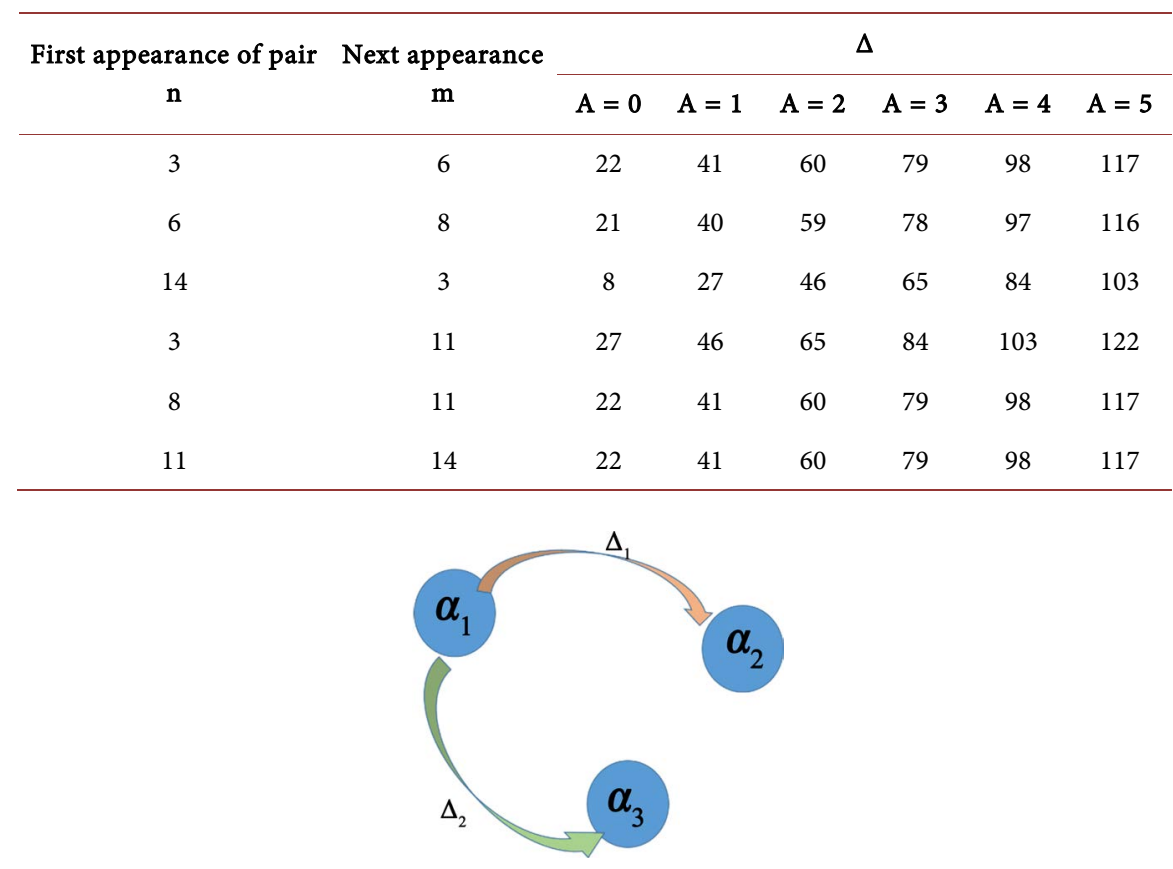

Figure 2. The schematic representation. 
the first new moon of the group and to the last. We obtain a new range and check if any part of this range falls in a cycle that contains the pair we are examining.

\begin{tabular}{ccc}
\hline & \multicolumn{2}{c}{ Year 6 } \\
\cline { 2 - 3 } & From & To (not including) \\
\hline \multirow{2}{*}{ +Remainder of cycle } & 3084 & 9949 \\
& $+69,715$ & $+69,715$ \\
& 72,799 & 79,664 \\
\hline
\end{tabular}

In Table 5, we see that this new range overlaps the range of cycles in which the pair appears in year $14(67,139-74,004)$. The interval from year 6 to year 14 is defined by formula 2 . Calculating the formula $(-6+14+1$ * 19$)$ we obtain 27 , the number years between the appearance of the pair. In the diagram, we replace $a_{1}$ with $6, a_{2}$ with 14 and $\Delta_{1}$ with 27 . This means that after the studied pair appears in year 6 of a cycle it will appear after 27 years in year 14 of a cycle.

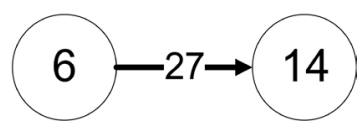

Since we will examine year 14 separately, we adjust the range so as not to include the range that includes year 14 and replace 72,799 with 74,004.

\begin{tabular}{ccc}
\hline & \multicolumn{2}{c}{ Year 6 } \\
\cline { 2 - 3 } & From & To (not including) \\
\hline & 3084 & 9949 \\
+ Remainder of cycle & $+69,715$ & $+69,715$ \\
& 72,799 & 79,664 \\
Adjusted range & 74,004 & 79,664 \\
+ Remainder of cycle & $+69,715$ & $+69,715$ \\
& 143,719 & 149,379 \\
\hline
\end{tabular}

From Table 5, we once again see that this new calculated range overlaps the range of cycles in which the pair appears in year 19. We once again calculate the interval using formula $2(-6+19+2 \star 19=51)$ and add this to our diagram. We exclude from our table the part of the range of new moons that fall within the appearance of year 19 and replace 149,379 with 143,719. We add the remainder of a cycle and find a new range $(31,994-35,844)$ that does not fall in the range of cycles that include the examined pair.

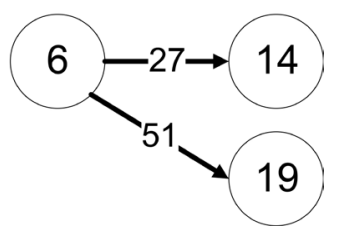


Once again, we add the remainder of a cycle and calculate a new range $(101,709-105,559)$ that falls entirely with the range of cycles that include year 8 . We calculate the new interval $(-6+8+4 * 19=78)$ and add it to our diagram. At this point we have finished with the possibilities of year 6 as we are entirely within the range of year 8 and will calculate that separately.

\begin{tabular}{ccc}
\hline & \multicolumn{2}{c}{ Year 6 } \\
\cline { 2 - 3 } & From & To (not including) \\
\hline +Remainder of cycle & 3084 & 9949 \\
& $+69,715$ & $+69,715$ \\
Adjusted range & 72,799 & 79,664 \\
+ Remainder of cycle & 74,004 & 79,664 \\
& $+69,715$ & $+69,715$ \\
Adjusted range & 143,719 & 149,379 \\
+ Remainder of cycle & 143,719 & 147,569 \\
(mod week) & $+69,715$ & $+69,715$ \\
+ Remainder of cycle & 31,994 & 35,844 \\
& $+69,715$ & $+69,715$ \\
& 101,709 & 105,559 \\
\hline
\end{tabular}

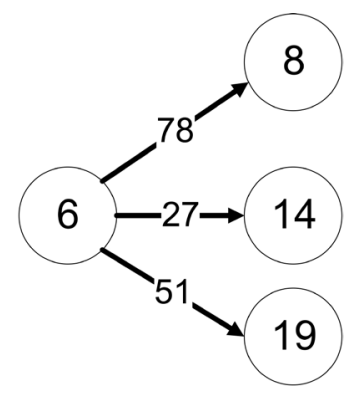

Using the same method, we do this for the other years: 3, 8, 11, 14, 17 and 19 and obtain Table 8.

6) Create a diagram of all the groups with arrows between the years listing the intervals

Combining all the diagrams together we obtain the following diagram.

Diagram 1 shows all the possible intervals between appearances of the pair of year codes bfg - bfe.

This can be summarized in the following table showing the starting year in which the paired year codes appear and a following year in which the paired year codes will appear and the length of the interval between them in years.

Table 9 shows the source year (left column), the target year, and the interval size Example: In the first row, we see an interval of 98 years from year 19 to year 3 , in the next column to year 8 with an interval of 27 years and in the third column an interval of 71 years to year 14 . 
Table 8. A summary table.

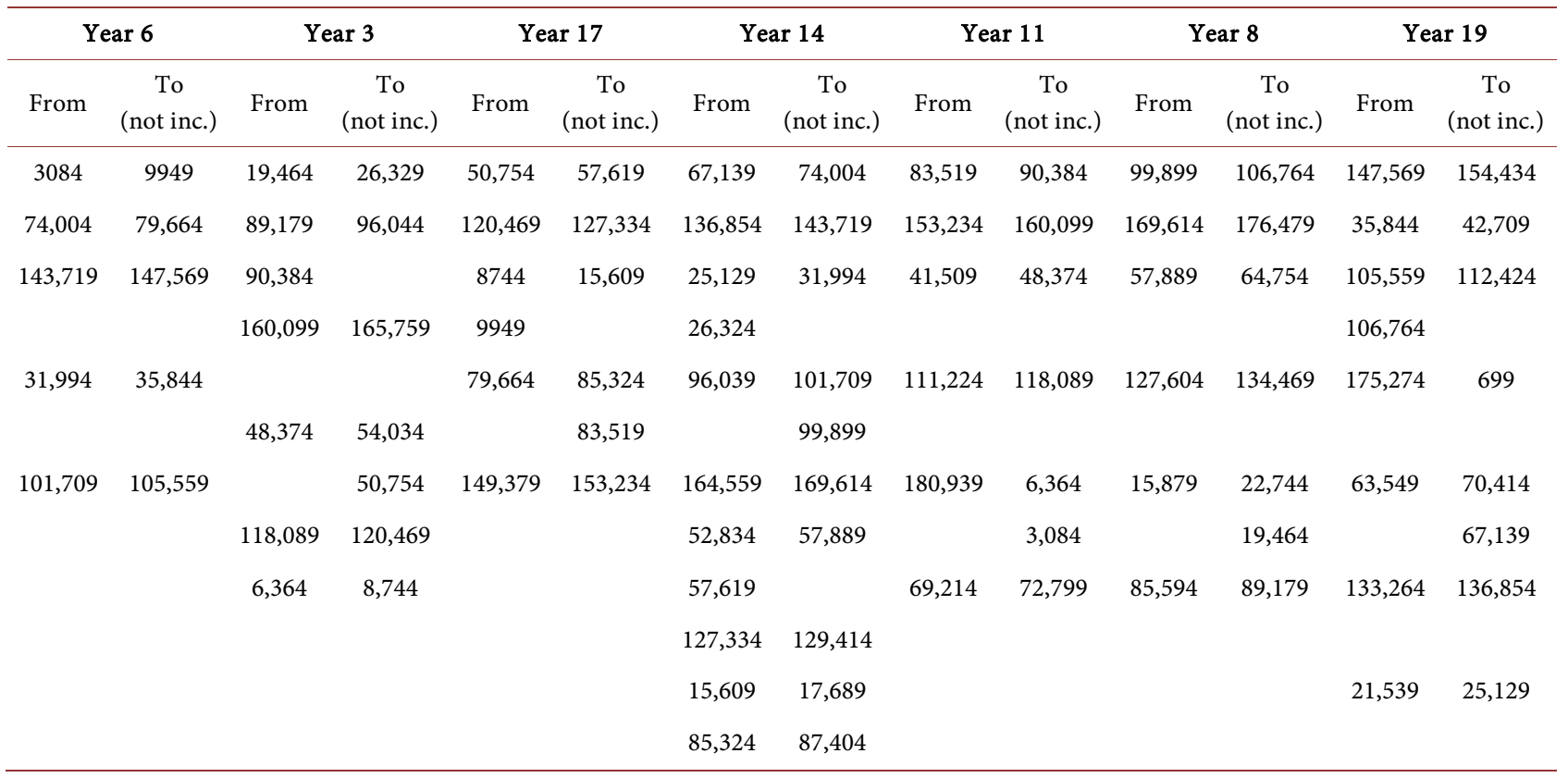

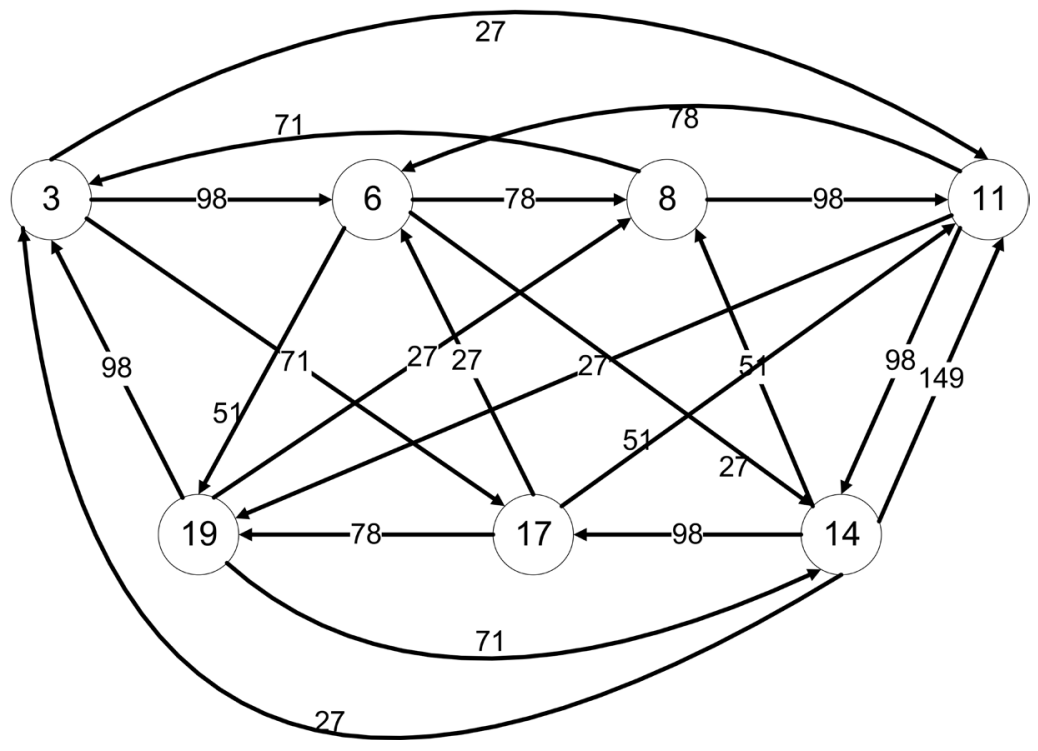

Diagram 1. The possible intervals between appearances of the pair of year codes bfg - bfe.

Table 9. Source year the target year, and the interval size.

\begin{tabular}{|c|c|c|c|c|}
\hline \multirow{2}{*}{$\begin{array}{c}\text { From year } \\
19\end{array}$} & \multicolumn{4}{|c|}{ To year (interval in years) } \\
\hline & $3(98)$ & $8(27)$ & $14(71)$ & \\
\hline 3 & $6(98)$ & $11(27)$ & $17(71)$ & \\
\hline 6 & $0(51)$ & $8(78)$ & $14(27)$ & \\
\hline 8 & $3(71)$ & $11(98)$ & & \\
\hline 11 & $0(27)$ & $6(78)$ & $14(98)$ & \\
\hline 14 & $3(27)$ & $8(51)$ & $11(149)$ & $17(98)$ \\
\hline 17 & $0(78)$ & $6(27)$ & $11(51)$ & \\
\hline
\end{tabular}




\section{7) Analysis of Diagram 1}

After preparing Diagram 1, we can formulate four rules concerning the relationships between the arrows.

a) The sum of a closed path. If $S$ equal the sum of the intervals in any closed path then $S(\bmod 19) \equiv 0$.

The trivial proof: we summarize all the arrows using formula 2 .

$$
\Delta_{n}=-n+m+19 A
$$

And we obtain:

$$
\begin{gathered}
\Delta_{1}=-a+b+19 A \\
\Delta_{2}=-b+c+19 B \\
\cdots \\
\Delta_{n}=-n+a+19 N \\
S=0+19 S \\
A, B \cdots N, S \in Z^{+}
\end{gathered}
$$

\section{QED}

b) The sum of a closed path that includes a reverse arrow. If a closed path includes an arrow in the opposite direction, then the path, not including the reverse arrow is equal to (mod 19) the value of the reverse arrow (mod 19) i.e. $\Delta_{1}+\Delta_{2} \equiv \Delta_{3}(\bmod 19)$.

Example

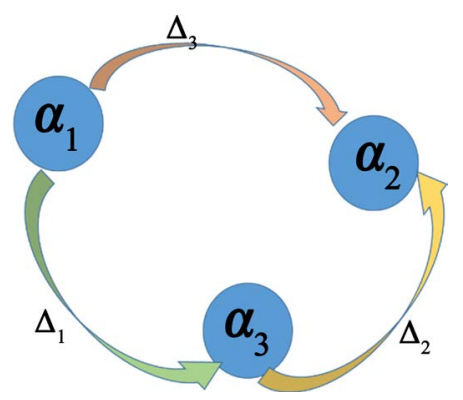

The trivial proof: we summarize all the arrows using formula 2.

$$
\begin{gathered}
\Delta_{1}=-a_{1+} a_{3+}+19 A \\
\Delta_{2}=-a_{3+} a_{2+}+19 B \\
\Delta_{3}=-a_{1+} a_{2+}+19 C \\
A, B, C \in Z^{+}
\end{gathered}
$$

QED

\section{Examples}



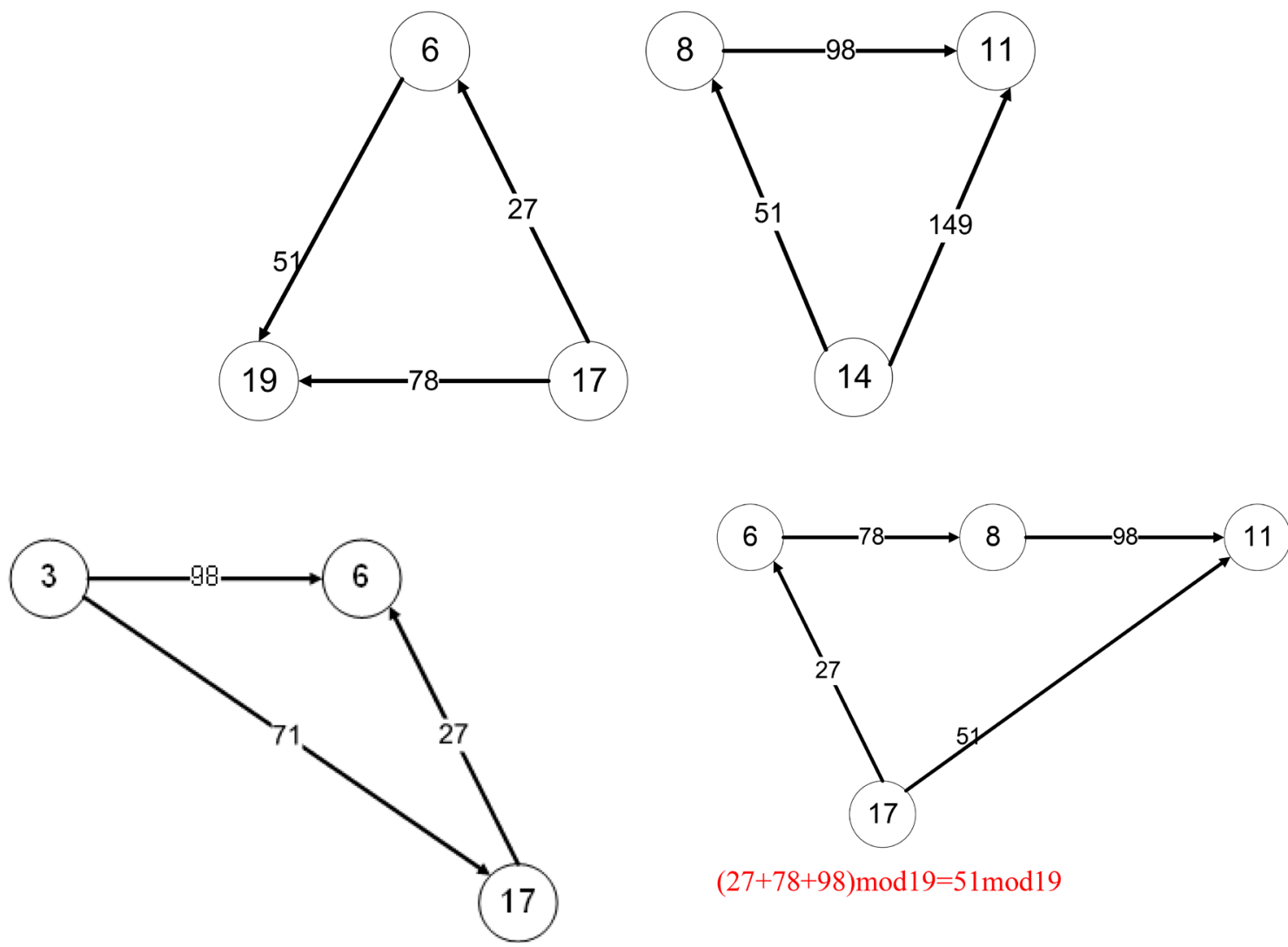

$(27+78+98) \bmod 19=51 \bmod 19$

c) Cyclicity of 247

Background: In the early literature on the Jewish calendar (especially the "Evronot"-books that summarized the rules of the calendar) There are tables known as the "cycle of Rav Nachshon Gaon". These tables include the year codes of 247 years ( 13 cycles of 19 years). The author of this table mistakenly thought that after 247 years the year codes will exactly repeat themselves. It was shown [8] p 61 that in $96.5 \%$ of the years the year codes do repeat themselves but in each 247 -year cycle there is at least 2 years in which the year codes change. In fact, after 247 years the time of the new moon of the new year has shifted by minus 905 parts. The Jewish calendar therefore does not have a 247-year cycle. Already in the 12th century when asked about this [9] answered that the calendar does not have a 247-year cycle.

After thirteen cycles of nineteen years (247 years the new moon will be 905 parts earlier than at the beginning of these 247 years (the cycle of Rav Nachshon Gaon).

If a range of new moons of a year is more than 905 parts then there will be paths that equal 247 years. If the range is more than 905 then after 247 years, we can return to the same year code in the 19-year cycle. In our example, the range is 6,865 parts and therefore there will be many times that the paths will equal 247 years. That is around each year there will be at least one path that is equal to 247 years.

Examples 


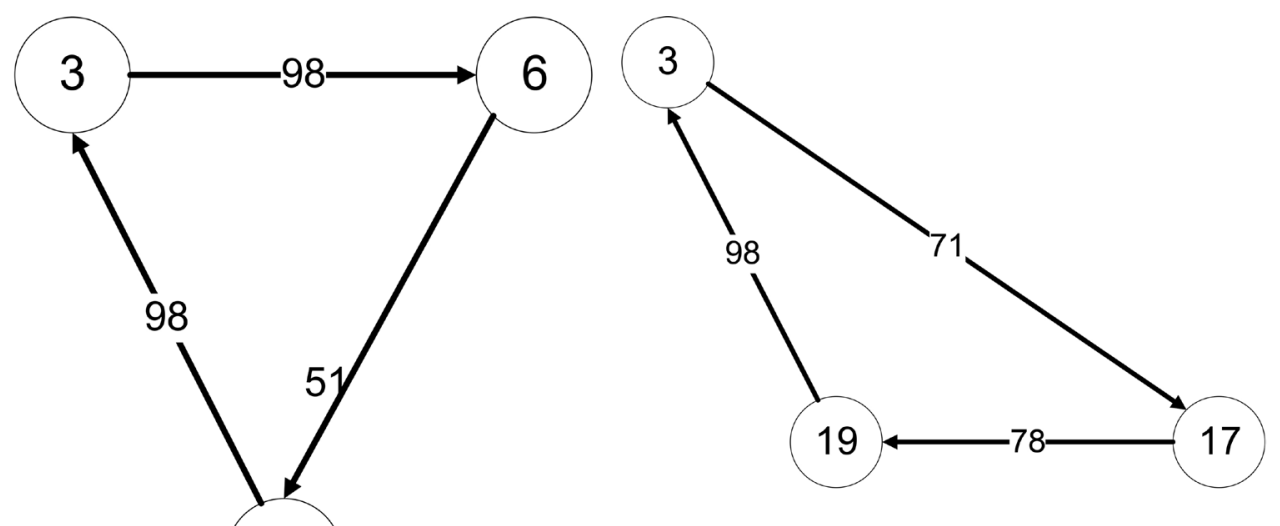

19

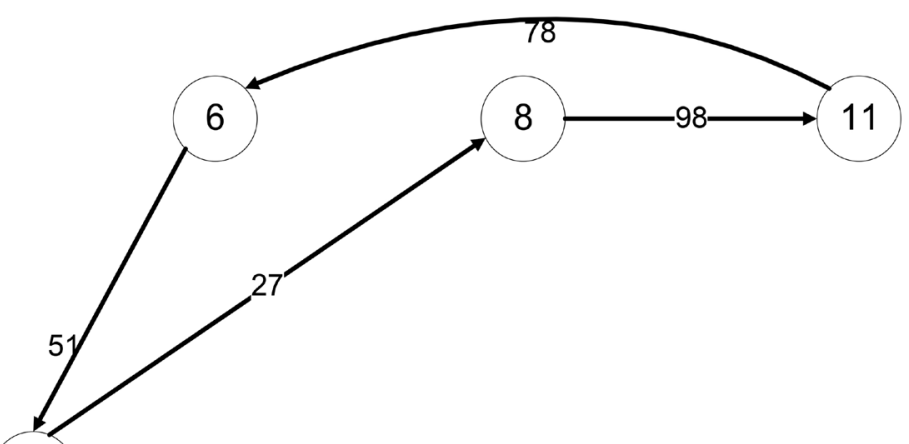

19
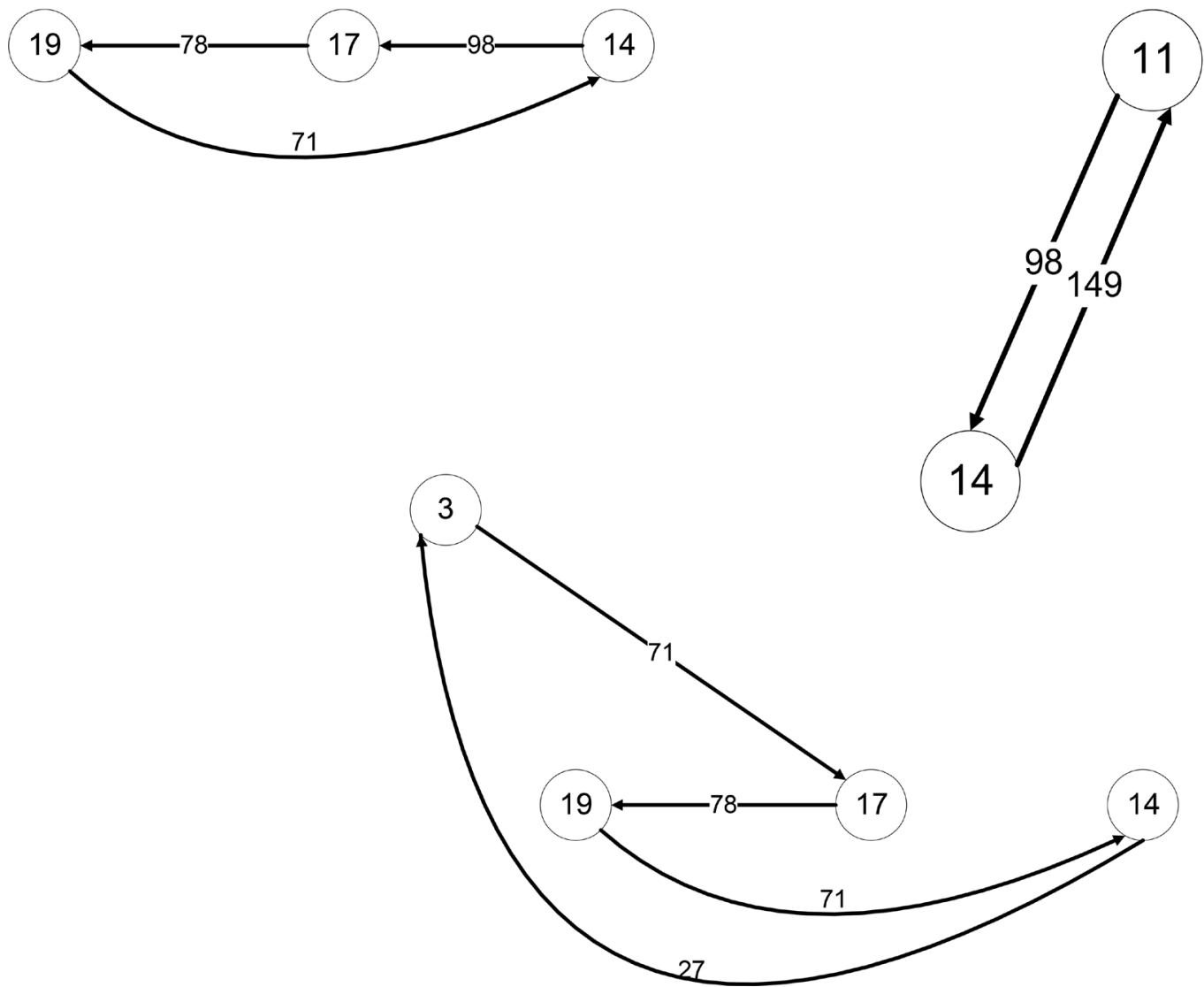


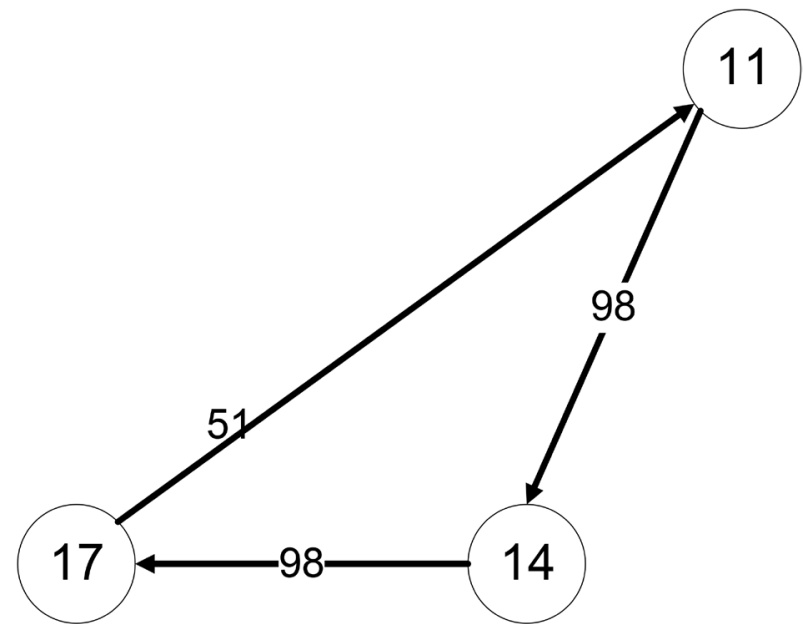

d) A requirement for a path that returns directly to the beginning, is that the range of the new moons for a specific year must be greater than the remainder of a 19-year cycle (13,943 occurrences).

$$
\Delta_{n}=19
$$

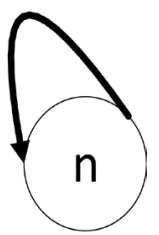

Trivial.

\subsection{Conclusion}

The table of sixty-one headings serves as a tool for calculating the year code for any particular year in the Jewish calendar. We demonstrated that using an algorithm it can also be used to find the intervals between the recurrence of pairs or any series of year codes. We have also shown that these intervals create a closed path in which the sum of the segments of the path, $S(\bmod 19) \equiv 0$.

\section{Conflicts of Interest}

The author declares no conflicts of interest regarding the publication of this paper.

\section{References}

[1] Stern, S. (2018) A Dispute between Sa'adia and Ben Meir-Part II, Lecture at the Hebrew Calendar Seminar, Bar Ilan University. https://www.youtube.com/watch?v=BZ0qacCyaZE\&list=PLXF_IJaFk-9DWxOnG84 eMXOxwxhpQY6D-\&index $=26$

[2] Sar-Shalom, R. (2009) She'arim La'luach Ha'ivry.

[3] Bornstein, H.J. (1922) Divrei Yimei HaIbur Haachronim p 292, Inside a magazine Ha-Tekufah. Vol. 16, Tel-Aviv’ A.Y. Shtibel ([1922]). 
[4] Raviv, E. (2010) Table and Fraction-The Molad Formula. Bekhol Derakheha Dae$h u, 22,31-54$. (In Hebrew)

[5] Ezra, I. (1874) Sefer HaIbur Published by Salomon Salman Chaim Halberstamm, Lyck.

[6] Ajdler, J.J. (2013) The Period of 689,472 Years in the Jewish Calendar and Its Applications in Frequency and Probability Problems. Bekhol Derakheha Daehu, 28, 30-40.

[7] Kennedy, E.S. (1964) Al-Khwarizmi on the Jewish Calendar. Scripta Mathematica, 27, 55-59.

[8] Raviv, E. (2015) Mathematical Studies in the Hebrew Calendar. Unpublished PhD Thesis, Bar Ilan University, Ramat Gan, 53-111.

[9] Ezra, I. (1847) Schene ha-meoroth, Berlin.

[10] Neugebauer, O. (1955) Astronomical Cuneiform Text, Babylonian Ephemerides of the Seleucid Period for the Motion of the Sun, the Moon, and the Planets. Institute for Advanced Study, by Lund Humphries in London, Princeton, 271-272.

[11] Jafee, Z.H. (1931) Korot Cheshbob HaIbur, Tel Aviv.

[12] Bornstein, H.J. (1904) The Dispute between Sa'adia Gaon and Ben Meir.

[13] Raviv, E. (2012) Synergy of "4 Gates" and "61 Rows" New Proposal to Determine the Characteristics of the Year in a 16 Row. Bekhol Derakheha Daehu, 26, 49-62. (In Hebrew)

[14] Raviv, E. (2014) The Mathematical Structure of " 4 Gate Table" and Prevalence Calculation in the Hebrew Calendar. Bekhol Derakheha Daehu, 28, 113-127. (In Hebrew)

[15] Raviv, E. (2013) 213 Row Table-A New Tool to Determine Type Percentages in the Hebrew Calendar. Bekhol Derakheha Daehu, 27, 63-76.

[16] Raviv, E. (2016) Jewish and Gregorian Calendars-Date Shifting. Bekhol Derakheha Daehu, 32, 61-80. (In Hebrew)

[17] Raviv, E. (2017) Series of "Siman Hashana"-Proof Tzvi Hirsch Jafee Formula. Bekhol Derakheha Daehu, 32, 45-54. (In Hebrew) 


\section{Appendix 1}

Brief explanation of the fixed Jewish calendar.

\section{Summary of the Rules}

\section{The Length of the Lunar Month}

The length of the lunar month in this calendar is based on the length of the average lunar month which was known to the ancient Babylonians and is 29.5 days 44 minutes and 31/3 seconds. (Neugebauer [10] found this value in Babylonian cuneiform texts).

In order to bring this value to a whole digit the hour is divided into 1080 parts so that the average lunar month is 765,433 parts. Since all the calculations of the fixed calendar are based on the weekly modulo (181,440 parts) one uses the monthly remainder to calculate how much the new moon of one month has advanced as compared to the previous month $[765,433 \bmod (181,440)=39,673$ parts].

\section{Synchronizing Lunar Months with Solar Years}

In order to synchronize the solar years with a whole number of lunar months the Jewish Calendar uses the 19-year Metonic cycle. In each cycle of 19 years there are 235 months broken up into 12 simple years of 12 months and 7 leap years of 13 months.

The $3^{\text {rd }}, 6^{\text {th }}, 8^{\text {th }}, 11^{\text {th }}, 14^{\text {th }}, 17^{\text {th }}$ and $19^{\text {th }}$ years are leap years.

In order to prepare a calendar for a specific year, three facts are necessary: 1) The day of the week on which the first day of the first month ("New Years") occurs. 2) Is the year defective, regular or full. 3) Is the year a simple or leap year (instead of the $3^{\text {rd }}$ fact it is customary to supply the day of the week on which the first day of the Jewish Holiday Passover occurs). These three facts provide us with the year code as will be explained.

\section{Determining the Day of the Week of New Years}

In order to determine on which day of the week New Years falls for a specific year we must first calculate on which day of the week the new moon occurs.

This average new moon is calculated on the basis of a base new moon (known as the "epoch" and in this case the new moon of year 1 is equal to Monday 5 hours and 204 parts). To this epoch we must add the remainders of the number of months between the epoch and the year we are calculating (we use modulo weeks in the calculation).

\section{Deferments}

After determining the day of the new moon, one has to check if New Years will fall on that day or deferred for one or two days. The rules that determine this are the 4 rules of deferment.

1) If the new moon falls on Sunday, Wednesday or Friday the new year will be deferred to the next day.

2) If the time of the new moon is equal to or greater than 18 hours then the 
New Year will be deferred to the next day. However, if the next day is Sunday, Wednesday or Friday then the New Year will be deferred by two days. (At the time of the dispute between Sa'adia Gaon from Babylon and Aharon Ben Meir from Israel the scholars deferred the new year only if it was greater than but not equal to 18 hours. Since the third and fourth deferments are a result of the first two this will change them to being greater than (and not equal to) Tuesday, 3 hours and 204 parts and greater than Monday 15 hours and 589 parts. See [11] page 176 in the footnotes, and [12] pages 64, 76, 86 footnote 2 and others).

3) In a simple year, if the new moon is equal or greater than Tuesday 9 hours and 204 parts, then the new year is deferred to Thursday.

4) In a year following a leap year if the new moon is equal or greater than Monday 15 hours and 589 parts, then the new year is deferred to Tuesday.

\section{The Length of the Year}

The length of the months of the year is fixed with the exception of the months Marcheshvan and Kislev. Their length is determined by the interval between the day of the week of this year's new years and next year's new years. In a plain year if the interval is 3 days then Marcheshvan and Kislev will both be 29 days. If the interval is 4 days then Marcheshvan will be 30 days and Kislev 29 days. If the interval is 5 days then Marcheshvan and Kislev will both be 30 days. In a similar way in a leap year for intervals of 5, 6 and 7 days these two months will have 29 or 30 days accordingly.

In Table 10, we have entered the length of the months and the years for all these 6 possibilities.

Table 10. The length of the months and the years for all these 6 possibilities.

\begin{tabular}{cccccccc}
\hline \multicolumn{2}{c}{ Leap Year } & & \multicolumn{5}{c}{ Plain Year } \\
\hline Month & full & regular & defective & Month & full & regular & defective \\
\hline Tishrei & 30 & 30 & 30 & Tishrei & 30 & 30 & 30 \\
Marcheshvan & 30 & 29 & 29 & Marcheshvan & 30 & 29 & 29 \\
Kislev & 30 & 30 & 29 & Kislev & 30 & 30 & 29 \\
Tevet & 29 & 29 & 29 & Tevet & 29 & 29 & 29 \\
Shvat & 30 & 30 & 30 & Shvat & 30 & 30 & 30 \\
First Adar & 30 & 30 & 30 & & & & \\
Adar & 29 & 29 & 29 & Adar & 29 & 29 & 29 \\
Nissan & 30 & 30 & 30 & Nissan & 30 & 30 & 30 \\
Iyar & 29 & 29 & 29 & Iyar & 29 & 29 & 29 \\
Sivan & 30 & 30 & 30 & Sivan & 30 & 30 & 30 \\
Tamuz & 29 & 29 & 29 & Tamuz & 29 & 29 & 29 \\
Av & 30 & 30 & 30 & Av & 30 & 30 & 30 \\
Elul & 29 & 29 & 29 & Elul & 29 & 29 & 29 \\
Total & $\mathbf{3 8 5}$ & $\mathbf{3 8 4}$ & $\mathbf{3 8 3}$ & Total & 355 & 354 & 353 \\
\hline & & & & & & &
\end{tabular}




\section{The Year Code}

In the fixed calendar there are 14 kinds of years. (7 simple years and 7 leap years. For a detailed explanation see [2] [4] [13]-[17]. Each year is designated by a combination of 3 letters. The first letter designates the day of the week of the first day of New Years. The second letter designates if the year is defective, regular or full (which determines the number of days in the year). The third letter designates the day of the week of the $15^{\text {th }}$ day of Nissan (Passover),

This combination of three letters is called the year code and can be found at the beginning of many published yearly calendars. The year code is expressed in Hebrew letters, For the purpose of this paper we will use the following abbreviations for the days of the week: Sunday-A, Monday-B, Tuesday-C, Thursday-E, Saturday-G and for the types of year Full-F, Regular-R, Defective-D.

For example: the year 5777 (first year of a 19-year cycle-a simple year).

Table 11. Example: the year 5777.

\begin{tabular}{ccccccc}
\hline \multicolumn{7}{c}{ New Moon Tishrei } \\
\hline year & day & hours & parts & Deferments & New years & Year code \\
\hline 5777 & 0 & 20 & 724 & New moon after 18 hours + Sunday & Monday & bdc \\
5778 & 5 & 5 & 520 & None & Thursday & erg \\
\hline
\end{tabular}

In Table 11, we see that according to the time of the new moon and the rules of deferment New years of 5777 falls on Monday (B) and New Years of 5778 falls on Thursday $€$. Between these days are 3 days and 50 weeks which add up to 353 days. Therefore the year 5777 is defective (D). 


\section{Appendix 2 (Table 12)}

Table 12. Clasical 61 Hadings Table.

\begin{tabular}{|c|c|c|c|c|c|c|c|c|c|c|c|c|c|c|c|c|c|c|c|c|c|c|c|c|}
\hline \multicolumn{25}{|c|}{ s-theoret } \\
\hline \multicolumn{5}{|c|}{ Borders } & & \multicolumn{19}{|c|}{ Year in the cycle } \\
\hline$n$ & & & parts & & & 1 & 2 & 3 & 4 & 5 & 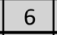 & & 8 & 9 & 10 & 11 & 12 & נI & 14 & 5 & 16 & 17 & 0 & \\
\hline 1 & 1 & & 408 & & 5325 & $\mathrm{dc}$ & efa & & fe & gda & $\mathrm{crg}$ & bfe & gdc & efa & cre & gfe & gfc & erg & bde & $\mathrm{gfc}$ & $\operatorname{erg}$ & bde & $\mathrm{gfc}$ & \\
\hline & & & & & 2 & & $\mathrm{fa}$ & $\mathrm{crg}$ & & a & $\mathrm{crg}$ & bfe & ffe & gda & cre & $\mathrm{fe}$ & $\mathrm{fc}$ & erg & de & gfc & $\mathrm{go}$ & $\mathrm{de}$ & $\mathrm{gfc}$ & efc \\
\hline & & & & & 1 & & a & $\operatorname{crg}$ & e & a & $\mathrm{crg}$ & fe & gfe & gda & cre & gfe & $\mathrm{fc}$ & erg & $\mathrm{de}$ & gfc & erg & $\mathrm{fg}$ & dc & $\mathrm{fc}$ \\
\hline 4 & & & & 44 & 2 & e & a & $\mathrm{rg}$ & e & $\mathrm{da}$ & $\mathrm{gg}$ & ee & $\mathrm{fe}$ & a & cre & $\mathrm{fe}$ & gfc & erg & de & $\mathrm{fcc}$ & $\mathrm{rg}$ & $\mathrm{fg}$ & $\mathrm{dc}$ & $\mathrm{fec}$ \\
\hline 5 & 1 & & 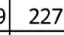 & 67. & 2 & 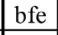 & la & $\operatorname{crg}$ & e & gfc & eda & cre & gfe & la & cre & gfe & $\mathrm{fc}$ & erg & de & gfc & erg & $\mathrm{fg}$ & $\mathrm{dc}$ & off \\
\hline 6 & 1 & 1 & 1 & & & & a & $\mathrm{rg}$ & e & fo & & cre & gfe & & erg & bde & & erg & de & $\mathrm{fc}$ & $\mathrm{rg}$ & $\mathrm{ig}$ & cc & \\
\hline 7 & 1 & 22 & 2051 & & 23 & & a & $\operatorname{crg}$ & e & fc & a & cre & gfe & 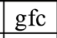 & erg & bde & 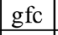 & erg & bfg & $\mathrm{bdc}$ & g & Ig & act & \\
\hline & 1 & 22 & & & & & a & & & 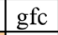 & & cre & $\mathrm{fe}$ & gfc & erg & bde & 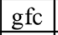 & erg & bfg & $\mathrm{ac}$ & & 018 & 4 & \\
\hline 9 & 2 & 0 & 040 & & & & ec & a & cre & $\mathrm{fc}$ & la & cre & gfe & 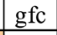 & erg & bde & gfc & erg & bfg & dc & 8 & bfg & $\mathrm{fe}$ & \\
\hline 10 & 2 & & 922 & & 2 & & $\mathrm{fc}$ & a & cre & $\mathrm{ffc}$ & 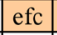 & erg & $\mathrm{de}$ & $f_{c}$ & erg & bde & gfc & erg & $\mathrm{bfg}$ & c) & 5 & bfg & bfe & \\
\hline 1. & 2 & 5 & 37 & & 9 & & $\mathrm{fc}$ & a & re & $\mathrm{fc}$ & c & erg & le & gfc & erg & bde & gfc & erg & bfg & & $\mathrm{fa}$ & $\mathrm{rg}$ & fe & \\
\hline 12 & 2 & 14 & 4 & 112 & 23 & e & $\mathrm{gfc}$ & $\mathrm{da}$ & $\mathrm{re}$ & gfc & efc & erg & $\mathrm{de}$ & gfc & erg & $\mathrm{fg}$ & bdc & erg & bfg & $\mathrm{dc}$ & $\mathrm{efa}$ & $\mathrm{crg}$ & bie & \\
\hline 13 & 2 & 14 & & & & & $\mathrm{fc}$ & la & re & fc & & erg & bde & gfc & erg & bfg & & & $\mathrm{gg}$ & & gda & + & & \\
\hline 14 & 2 & 15 & & & 267 & 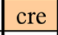 & $\mathrm{fc}$ & a & cre & fc & & \begin{tabular}{|l|} 
erg \\
\end{tabular} & bde & gfc & erg & $\mathrm{gg}$ & 6 & erg & $\mathrm{fg}$ & e & $\mathrm{da}$ & $\mathrm{crg}$ & It & \\
\hline 15 & 2 & 18 & & & 2 & $\mathrm{re}$ & $f c$ & ic & $\mathrm{rg}$ & lc & & rg & le & gfc & erg & $\mathrm{fg}$ & & erg & 19 & bee & dat & 48 & & $\mathrm{dc}$ \\
\hline 16 & 2 & 20 & & & 5 & re & fc & fc & $\mathrm{g}$ & c & c & erg & e & $\mathrm{gf}$ & erg & $\mathrm{gg}$ & & $t$ & t & bfe & gda & crg & bfe & \\
\hline 17 & 3 & & & & 416 & re & $\mathrm{Ic}$ & & $\mathrm{g}$ & $c$ & c. & erg & bde & gfc & erg & $\mathrm{gg}$ & & a & I & bfe & 4 & 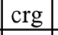 & bfe & 5 \\
\hline 18 & 3 & 5 & & & 23 & re & $\mathrm{ffc}$ & & $\mathrm{g}$ & & & erg & bfg & & erg & 1 & & eta & 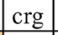 & & 4 & 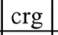 & & 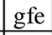 \\
\hline 1 & 3 & & & & 2 & e & $\mathrm{fc}$ & & erg & $\mathrm{c}$ & c & erg & $\mathrm{fg}$ & & erg & $\mathrm{gg}$ & & gda & c & & 1 & & & 10 \\
\hline 20 & 3 & & & 39 & & & $f_{c}$ & c & $g$ & c & ce & erg & $\mathrm{g}$ & & erg & $\mathrm{g}$ & & gda & & & \begin{tabular}{|l|} 
gfc \\
\end{tabular} & & & 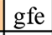 \\
\hline 21 & 3 & & & & 2 & & 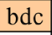 & & $\mathrm{g}$ & $c$ & & erg & $\mathrm{g}$ & & erg & $\mathrm{g}$ & & & 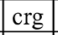 & & gfc & & & $\mathrm{fe}$ \\
\hline 22 & 3 & 9 & & & & & ic & & $\mathrm{g}$ & 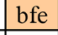 & Ic & erg & & & erg & $\mathrm{g}$ & & & & $\mathrm{e}$ & gf & & & 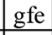 \\
\hline 23 & 3 & 11 & & & 9 & & lc & & $\mathrm{g}$ & $\mathrm{Ie}$ & ic & erg & 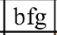 & & efa & rg & & $\mathrm{gd}$ & & bfe & gfe & & & 5 \\
\hline 24 & 3 & 20 & & & 2 & $\mathrm{~g}$ & $\mathrm{dc}$ & & erg & & Ic & erg & 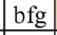 & & gda & S & & $\mathrm{gda}$ & 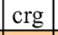 & bfe & gfc & & & SIe \\
\hline 25 & 3 & 20 & j & & 2 & $\operatorname{rg}$ & $\mathrm{dc}$ & & erg & $\mathrm{fe}$ & f & erg & 8 & & gda & 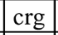 & & gfc & eda & cre & gfc & 20 & $\mathrm{cr}$ & fe \\
\hline 26 & 3 & 22 & 210 & 94 & 1 & erg & dc & & $\lg$ & $\mathrm{fe}$ & t & erg & 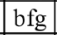 & & $\mathrm{da}$ & 78 & & $\mathrm{tc}$ & da & cre & $=$ & $E$ & & \\
\hline 2 & 4 & 0 & & & 2 & gg & $\mathrm{fe}$ & ic & erg & $\mathrm{e}$ & ic & erg & $\mathrm{fg}$ & & gda & c & & $\mathrm{tc}$ & & cre & gfc & & & \\
\hline 28 & 4 & & & & & & e & lc & $\mathrm{g}$ & fe & & efa & to & & $\mathrm{a}$ & & & gfc & & & gf & & & \\
\hline 29 & 4 & & & & 23 & & $e$ & ic & erg & & e & gda & c & & gda & & & c & & re & gfc & & $\mathrm{g}$ & \\
\hline 30 & 4 & 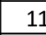 & & & 2 & & 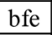 & $\mathrm{c}$ & erg & & et & gda & 0 & & 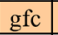 & a & & gfc & & & gf & & & \\
\hline 31 & 4 & 14 & & & 5 & $\mathrm{~g}$ & e & ic & erg & $\mathrm{fe}$ & gfe & gda & $f$ & & gfc & 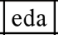 & cre & gfc & & erg & & $\mathrm{c}$ & & \\
\hline 32 & 4 & 18 & & & & $\mathrm{~g}$ & $\mathrm{fe}$ & c & efa & 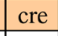 & gfe & gda & c & $\mathrm{b}$ & gfc & $f$ & cre & $\mathrm{gfc}$ & & erg & bdc & efc & & \\
\hline 33 & 5 & 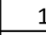 & & & 1 & $\mathrm{rg}$ & $\mathrm{fe}$ & le & 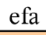 & cre & gf & gda & c & & gfc & $T$ & cre & gfc & & erg & & efc & erg & \\
\hline 34 & 5 & 2 & & & 23 & rg & $f \mathrm{fe}$ & gfe & gda & - & gfe & gda & to & $\mathrm{b}$ & gfc & $\mathrm{a}$ & cre & gfc & & er & & & erg & \\
\hline 3 & 5 & & & & & & fe & gfe & a & $\mathrm{re}$ & gfe & gfc & $a$ & & gfc & a & $\mathrm{c}$ & gfc & & $\operatorname{erg}$ & & efc & erg & \\
\hline 36 & 5 & & & & 2 & & e & 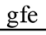 & & & gfe & gfc & $\mathrm{a}$ & & gfc & + & & bdc & & erg & & & $\mathrm{e}$ & \\
\hline 37 & 5 & & & & & & es & e & a & 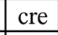 & $\mathrm{g}$ & \begin{tabular}{|l|} 
gfc \\
\end{tabular} & $\mathrm{a}$ & & gfc & t & e & 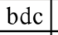 & 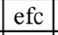 & erg & bfe & $\mathrm{gdc}$ & & bfg \\
\hline I & 5 & & & & 2 & & $\mathrm{e}$ & e & a & e & gie & gfc & a & & gfc & & e & c) & & & 1 & & & Dig \\
\hline 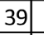 & 5 & 0 & & & & & re & & gfc & 2 & $b c$ & \begin{tabular}{|l|} 
gfc \\
\end{tabular} & at & & gfc & & & T & & & 1 & $g_{c}$ & & bog \\
\hline 401 & 5 & & & & 2 & & $\mathrm{re}$ & & 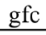 & & $\mathrm{b}$ & gfc & 4 & e & gfc & fc & & bdc & & & bfe & gdc & & \\
\hline 41 & 5 & 20 & & & 2 & & re & & gfc & 5 & $b c$ & gfc & efc & $\mathrm{e}$ & bdc & & & t & & & bfe & gdc & & \\
\hline 42 & 5 & 20 & & & & & cre & & $\mathrm{gfc}$ & erg & & c & $\mathrm{ffc}$ & erg & $\mathrm{bdc}$ & & $\mathrm{g}$ & bfe & $\mathrm{dc}$ & & $\mathrm{fe}$ & gdc & & \\
\hline 43 & 5 & 22 & & & & & e & & $c$ & & & gfc & & & & & & & E & & & $\mathrm{dc}$ & & \\
\hline 44 & 6 & & & & & & erg & e & gfc & $\mathrm{g}$ & & gfc & te & & c) & - & & 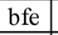 & cc| & & bfe & gdc & H & \\
\hline 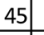 & 6 & & & & & & erg & e & $\mathrm{gfc}$ & $\mathrm{g}$ & $\mathrm{b}$ & gfc & $f$ & es & 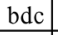 & 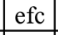 & & $t$ & c) & & 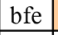 & gfe & & 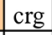 \\
\hline I & 6 & 11 & & & 2 & & erg & & $\mathrm{gfc}$ & 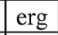 & $\mathrm{b}$ & $\mathrm{bdc}$ & & & & & & & $\mathrm{dc}$ & & e & & & \\
\hline 17 & 6 & I. & & & & & $\mathrm{rg}$ & e & $\mathrm{gfc}$ & & & bdc & E & & ore & te & & & Ic & & 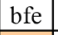 & & & \\
\hline 48 & 6 & & & & & & $\mathrm{~g}$ & & gfc & & & bdc & e & & 18 & & & b & (c] & & & & & \\
\hline 49 & 6 & 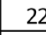 & & & 2 & & & & gf & & & bot & & & & ic & & & & & & & & \\
\hline 50 & 6 & 22 & & & & & $\mathrm{e}$ & & & & & & & & bfe & ic & & & & & & & & \\
\hline 51 & 0 & & & & 23 & & et & & & & & bdc & & & & ic & & & & & & & & \\
\hline 52 & 0 & & & & 26 & & $\mathrm{e}$ & & & & & bfe & gdc & & bfe & gdc & & et & 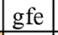 & 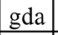 & e & L & gfc & ad \\
\hline \begin{tabular}{|l|l}
53 \\
\end{tabular} & 0 & & & & 23 & & erg & & 0 & $\mathrm{~g}$ & & bfe & ic & & bee & gdc & & cre & 2 & gda & e & e & gfc & $\mathrm{da}$ \\
\hline 54 & 0 & & & & & & erg & & & $\mathrm{g}$ & 01 & 01 & IC] & e & 01 & $\mathrm{dc}$ & & Cre & & & $\mathrm{g}$ & bde & & \\
\hline 55 & 0 & 9 & & & & & $c$ & & $b$ & & & bfe & & & bfe & $\mathrm{dc}$ & & cre & & & & & & $\mathrm{d} \mathrm{z}_{\mathrm{z}}$ \\
\hline 56 & 0 & & & & & & $\mathrm{erg}$ & & & & & $\mathrm{b}$ & & & bfe & & & ete & & & $\mathrm{g}$ & & & \\
\hline 57 & 0 & 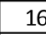 & & & & & & & & & & & & & & & & & & & & & & \\
\hline 58 & 0 & & & & & & & & & & & & & & & & & & & & & & & \\
\hline 59 & 0 & 18 & & & & & & b & & & & b & & & $\mathrm{b}$ & gfe & & & 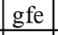 & c & & bde & gfc & efc \\
\hline 00 & 0 & 20 & 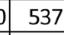 & & & & & & bf & & & b & & & cre & gf & & 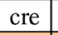 & 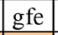 & 5 & & & gfc & efc \\
\hline 61 & 0 & 20 & 560 & 2160 & 416 & $b d c$ & erg & b. & bfe & gda & Ic & bfe & gdc & efa & cre & gfe & gfc & erg & bde & gfc & rg & bde & gfc & \\
\hline
\end{tabular}

